\title{
Synergistic regenerative therapy of thin endometrium by human placenta-derived mesenchymal stem cells encapsulated within hyaluronic acid hydrogels
}

Yifeng Lin ${ }^{1 \dagger}$, Shunni Dong ${ }^{2 \dagger}$, Xiaohang Ye ${ }^{1 \dagger}$, Juan $\mathrm{Liu}^{1}$, Jiaqun $\mathrm{Li}^{3}$, Yanye Zhang ${ }^{3}$, Mixue $\mathrm{Tu}^{3}$, Siwen Wang ${ }^{3}$, Yanyun Ying ${ }^{3}$, Ruixue Chen ${ }^{3}$, Feixia Wang ${ }^{3}$, Feida $\mathrm{Ni}^{3}$, Jianpeng Chen ${ }^{3}$, Binyang Du ${ }^{2 *}$ and Dan Zhang ${ }^{1,3^{*}}$ (D)

\begin{abstract}
Background: Thin endometrium is a primary cause of defective endometrial receptivity, resulting in infertility or recurrent miscarriage. Much effort has been devoted toward regenerating thin endometrium by stem cell-based therapies. The human placenta-derived mesenchymal stem cells (HP-MSCs) are emerging alternative sources of MSCs with various advantages. To maximize their retention inside the uterus, we loaded HP-MSCs with cross-linked hyaluronic acid hydrogel (HA hydrogel) to investigate their therapeutic efficacy and possible underlying mechanisms.

Methods: Ethanol was injected into the mice uterus to establish the endometrium-injured model. The retention time of HP-MSCs and HA hydrogel was detected by in vivo imaging, while the distribution of HP-MSCs was detected by immunofluorescence staining. Functional restoration of the uterus was assessed by testing embryo implantation rates. The endometrial morphological alteration was observed by H\&E staining, Masson staining, and immunohistochemistry. In vitro studies were further conducted using EdU, transwell, tube formation, and western blot assays.

Results: Instilled HP-MSCs with HA hydrogel (HP-MSCs-HA) exhibited a prolonged retention time in mouse uteri than normal HP-MSCs. In vivo studies showed that the HP-MSCs-HA could significantly increase the gland number and endometrial thickness $(P<0.001, P<0.05)$, decrease fibrous area $(P<0.0001)$, and promote the proliferation and angiogenesis of endometrial cells (as indicated by Ki67 and VEGF, $P<0.05, P<0.05$, respectively) in mice injured endometrium. HP-MSCs-HA could also significantly improve the embryo implantation rate $(P<0.01)$ compared with the ethanol group. Further mechanistic study showed the paracrine effects of HP-MSCs. They could not only promote the proliferation and migration of human endometrial stromal cells via the JNK/Erk1/2-Stat3-VEGF pathway but also
\end{abstract}

\footnotetext{
*Correspondence: duby@zju.edu.cn; zhangdan@zju.edu.cn

${ }^{\dagger}$ Yifeng Lin, Shunni Dong and Xiaohang Ye have contributed equally to this work

'Key Laboratory of Women's Reproductive Health of Zhejiang Province and Department of Reproductive Endocrinology, Women's Hospital, Zhejiang University School of Medicine, Hangzhou 310006, Zhejiang,

China

${ }^{2}$ MOE Key Laboratory of Macromolecular Synthesis and Functionalization,

Department of Polymer Science and Engineering, Zhejiang University, Hangzhou 310027, China

Full list of author information is available at the end of the article
} permits use, sharing, adaptation, distribution and reproduction in any medium or format, as long as you give appropriate credit to the original author(s) and the source, provide a link to the Creative Commons licence, and indicate if changes were made. The images or other third party material in this article are included in the article's Creative Commons licence, unless indicated otherwise in a credit line to the material. If material is not included in the article's Creative Commons licence and your intended use is not permitted by statutory regulation or exceeds the permitted use, you will need to obtain permission directly from the copyright holder. To view a copy of this licence, visit http://creativecommons.org/licenses/by/4.0/. The Creative Commons Public Domain Dedication waiver (http://creativeco mmons.org/publicdomain/zero/1.0/) applies to the data made available in this article, unless otherwise stated in a credit line to the data. 
facilitate the proliferation of glandular cells via Jak2-Stat5 and c-Fos-VEGF pathway. In turn, the increased VEGF in the endometrium promoted the angiogenesis of endothelial cells.

Conclusion: Our study suggested the potential therapeutic effects and the underlying mechanisms of HP-MSCs-HA on treating thin endometrium. HA hydrogel could be a preferable delivery method for HP-MSCs, and the strategy represents a promising therapeutic approach against endometrial injury in clinical settings.

Keywords: Human placenta-derived mesenchymal stem cells, Hyaluronic acid hydrogels, Thin endometrium, Endometrial repair, Regeneration mechanisms

\section{Graphical abstract}

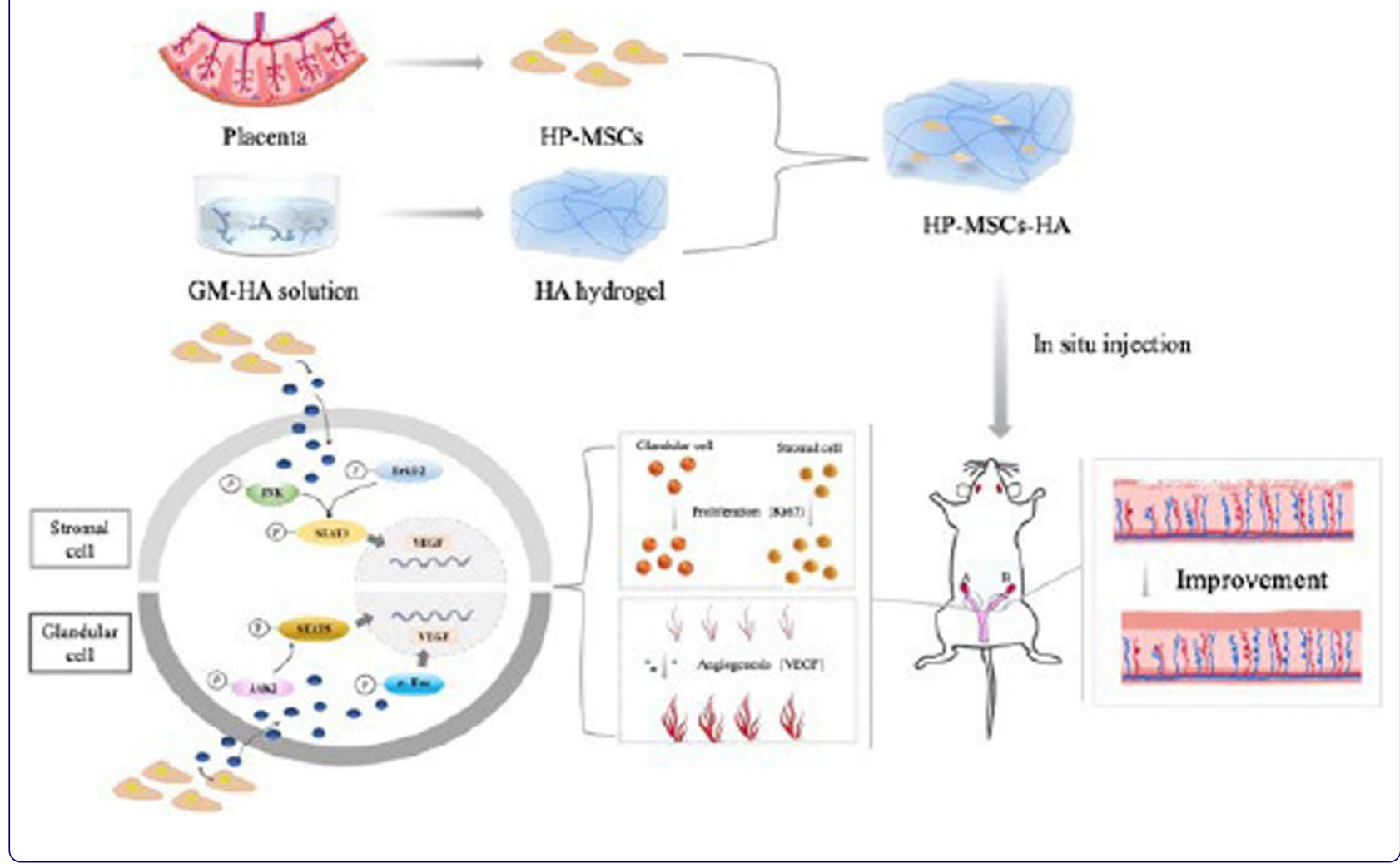

\section{Background}

Infertility is estimated to affect $8 \%-12 \%$ of reproductiveaged couples worldwide and is often associated with significant physical and emotional stress [1]. Assisted reproductive technologies (ART) is a great solution for most causes of infertility, such as ovulatory dysfunction, male factor infertility, and tubal disease [2]. However, the implantation rate is still as low as $20-30 \%$ due to poor endometrial receptivity $[3,4]$, among which thin endometrium is a primary cause of failed embryo transfer, resulting in long-term infertility and negative family outcomes. Embryo implantation is first nourished by endometrial gland secretions. However, physical (induced abortion, frequent intrauterine operation, radiation) and biochemical (infection, endocrine-disrupting chemical) injury will impair the normal growth of the endometrium, resulting in thin endometrium, a common disease in women of reproductive age $[5,6]$. In assisted reproduction, an endometrial thickness of $8-12 \mathrm{~mm}$ is considered normal for embryo implantation, a thickness of less than $7-8 \mathrm{~mm}$ is commonly defined as thin endometrium [6-9]. Previous studies have reported a significant correlation between thin endometrium and infertility. The mean endometrial thickness was significantly higher in pregnant women than non-pregnant women [10-13]. Therefore, improving endometrial thickness in patients with thin endometrium will certainly benefit the pregnancy process and achieve positive family outcomes.

Over the years, several treatment modalities have been suggested for thin endometrium, including hysteroscopic adhesiolysis, hormonal manipulation, and adjuvants (aspirin, luteal estradiol, sildenafil citrate, granulocyte colony-stimulating factor) [14]. Despite the vast diversity of treating methods, only a minor facilitating change is 
reported in the endometrium thickness and implantation rates without robust evidence, especially for severe endometrium-injured patients [14]. Thus, treatment of thin endometrium remains a challenge, and future studies are crucial to improving pregnancy outcomes in patients with thin endometrium.

In the field of cell therapy, stem cell transplantation has pioneered novel approaches for the biomedical treatment of injured endometrium $[15,16]$. MSCs are undifferentiated pluripotent stem cells with the characteristics of paracrine, immune regulation, and multi-directional differentiation [17]. The origins of MSCs include autologous bone marrow, autologous peripheral blood, autologous muscle, allogeneic fetal liver, allogeneic umbilical cord, etc. MSCs infusion therapy has been applied in animal models and preclinical experiments of various diseases and has shown favorable outcomes in relieving animal symptoms and improving patients' comprehensive signs $[17,18]$. For the therapy of thin endometrium, there are only a handful of reported cases hitherto, among which bone marrow-derived mesenchymal stem cells (BMMSCs) are principally studied, while the major focus is on the therapeutic results, yet the underlying mechanism is not clear [19]. However, BM-MSCs are difficult to acquire for large-scale uses owing to the invasive process of bone marrow collection, which leads to an increased risk of microbial infection. In contrast, the allogeneic placenta is a bona fide candidate origin of MSCs. Abundant MSCs have been found in the placenta, the process of placenta collecting noninvasive, which causes no harm to the fetus and the mother $[20,21]$. Moreover, owing to the low immunogenicity of HP-MSCs, they can be applied to treat animal models and patients without causing immune responses [5-9]. Besides, recent research indicates that HP-MSCs also show vigorous expansion ability and greater proliferation capacity than umbilical cord-derived MSCs (UC-MSCs) [22]. Taken together, all these favorable conditions make HP-MSCs to be a novel alternative source for stem cell therapy in treating thin endometrium.

Physiologically, the uterus is closely interlinked with the vagina. Thus, the traditional in situ instillation of HP-MSCs tends to cause part of the cell suspension to slip out of the uterus via the vagina, limiting the maximal retention efficacy of HP-MSCs. Several novel strategies have been adopted to enhance the retention time of stem cells, including hyaluronic acid (HA) and Pluronic F-127 [15, 23-27]. Among those, HA hydrogel is a promising candidate for the encapsulation and release of HP-MSCs for endometrial therapy. The existence of hyaluronidase in the endometrium can effectively degrade HA in case that HA stays in the uterine cavity persistently without decomposition [28]. Moreover, HA hydrogel has a three-dimensional cross-linked network and shows low interfacial tension and adhesion characteristics, which can provide structural and mechanical support for adjacent cells. As a result, HP-MSCs can be gradually released from the hydrogel to achieve the optimal therapeutic effect [26].

The human endometrium is a complex and dynamic tissue that consists of an outer functionalis layer and an inner basalis layer. The functionalis is mainly composed of glandular cells and stromal cells, while the inner basalis layer contains mainly stromal cells [29]. The two layers are nourished by spiral arteries. Consequently, exploring the effects and underlying mechanisms of HP-MSCs on primary human endometrial cells and human umbilical vein endothelial cells (HUVECs) might help us improve cell therapy for the thin endometrium.

In the present study, we encapsulate the HP-MSCs within a HA hydrogel(HP-MSCs-HA)and then evaluate the therapeutic effects of HP-MSCs-HA on the murine model of thin endometrium in vivo, including the embryo implantation rate, the endometrial thickness, the number of glands, the degree of fibrosis, and the proliferation and angiogenesis. Furthermore, we probe the potential molecular mechanism and signal pathway of HP-MSCs on endometrial stromal and glandular cells in vitro.

\section{Methods \\ Materials}

Hyaluronic acid (HA, 97\%) and glycidyl methacrylate (GMA, 98\%) were purchased from Maclin Biochemical Co. Ltd (Shanghai, China) and J\&K Chemical Ltd (Beijing, China), respectively. 2-hydroxy-4'-(2-hydroxyethyl)2-methylpropiophenone (Photoinitiator Irgacure 2959, 99\%) was obtained from Aladdin Bio-Chem Technology Co. Ltd (Shanghai, China). Fluorescein O-methacrylate (FMA, 97\%) was acquired from Sigma-Aldrich (Pennsylvania, USA). All chemicals were used as received without further purification.

Identified HP-MSCs were kindly provided by the College of Life Sciences-iCell Biotechnology Regenerative Biomedicine Laboratory, Zhejiang University. The identification results of these HP-MSCs were provided in supplement materials. The cells were cultured in basic DMEM/F12 medium (Hyclone, Logan, UT, USA) containing 10\% fetal bovine serum (FBS, Biological Industries, Kibbutz Beit-Haemek, Israel), 1\% penicillin (Geno, Hangzhou, China) at $5 \% \mathrm{CO}_{2}$ and $37{ }^{\circ} \mathrm{C}$ as previously optimized [30, 31]. HUVECs were purchased from ScienCell company (8000, California, USA) and were cultured in ECM medium (1001, ScienCell, California, USA) at $37^{\circ} \mathrm{C}$ with $5 \% \mathrm{CO} 2$. 


\section{Preparation and characterization of HA hydrogel}

The polymerizable HA was prepared via the chemical modification of HA by using GMA, as shown in Fig. 1A. Briefly, $0.5 \mathrm{~g} \mathrm{HA}$ was dissolved in $100 \mathrm{~mL}$ mixture of $\mathrm{N}, \mathrm{N}$-dimethylformamide (DMF), and phosphate buffer saline (PBS) solution $(0.01 \mathrm{M}, \mathrm{pH}=7.40)$ with a volume ratio of $1: 1$ overnight. The mixture was subsequently mixed with $3.35 \mathrm{~g}$ of triethylamine (TEA) for $30 \mathrm{~min}$. Then, $6.65 \mathrm{~g}$ GMA was added to the mixture and stirred for 5 days at room temperature. The reaction mixture was precipitated in 20 times excess acetone solution. The precipitates were collected and dried in a vacuum oven. The products were purified by dialysis in deionized water for 3 days and further dried by lyophilization, leading to the final GMA functionalized HA powders, coded as GM-HA. To prepare HA hydrogel, $10 \mathrm{mg}$ GM-HA were dissolved in $1 \mathrm{~mL}$ aqueous solution containing 1\%o Irgacure 2959 photoinitiator. The mixed solution was then exposed to $365 \mathrm{~nm}$ UV light for $15 \mathrm{~min}$, leading to the formation of HA hydrogels. Similarly, the fluorescent HA hydrogel was synthesized by the polymerization between GM-HA $(10 \mathrm{mg})$ and FMA (1 mg) under exposure to $365 \mathrm{~nm}$ UV light for 15 min with the same concentration of photoinitiator, which was applied to observe the retention of HA hydrogel in the endometrium.

${ }^{1} \mathrm{H}-\mathrm{NMR}$ spectrum of GM-HA was recorded on a $400 \mathrm{MHz}$ Bruker NMR instrument with $\mathrm{D}_{2} \mathrm{O}$ as a solvent. Fourier transform infrared (FT-IR) spectra of GM-HA and HA hydrogel were obtained by a Bruker Vector 22 spectrometer. The rheological measurement of HA hydrogel was carried out on DHR2-2183 rheometer at $37^{\circ} \mathrm{C}$. The morphologies of HA and HA hydrogel were observed by Nova Nano scanning electron microscopy (SEM 450, Thermo FEI). The HA and lyophilized HA hydrogel power were evenly spread on the conductive glue and purged three times with an ear wash ball for SEM samples. The prepared samples were sprayed with platinum for $60 \mathrm{~s}$ before SEM observation. After that, 500 $\mu \mathrm{L}$ HA hydrogel was mixed with $4 \times 10^{6} \mathrm{HP}-\mathrm{MSCs}$ and incubated at $37^{\circ} \mathrm{C}$ for $10 \mathrm{~min}$ to prepare HP-MSCs-HA, and the mouse was injected with $25 \mu \mathrm{L}$ HP-MSCs-HA per uterus.

\section{Isolation and culture of Human stromal and glandular cells} Twenty female patients aged between 24-48 years old with regular menstrual cycles (21-35 days) were recruited at Women's Hospital of Zhejiang University,

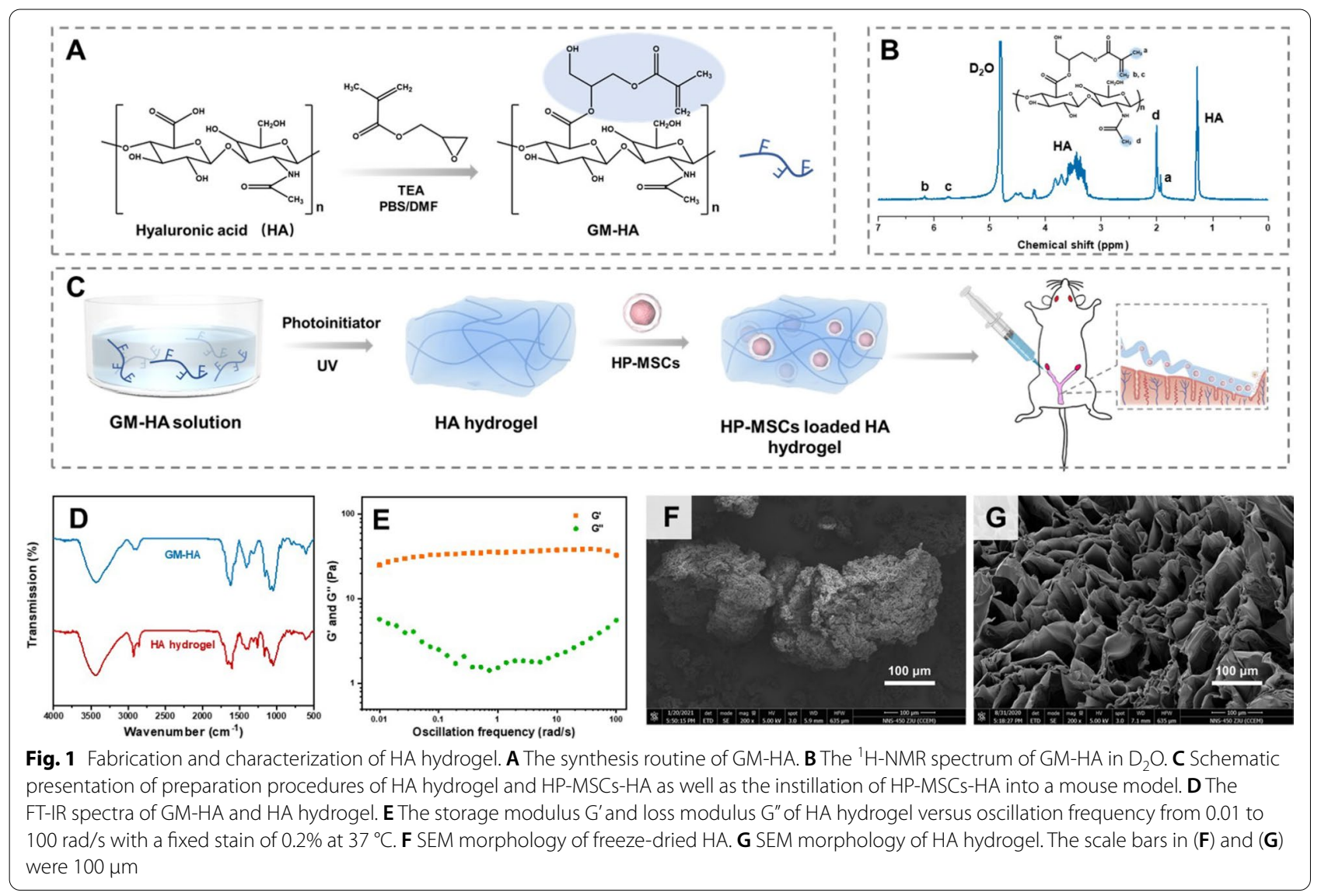


China. They haven't received hormone therapy at least three months before surgery. All the patients underwent hysteroscopy and endometrial biopsy during the infertility examination. Stromal and glandular cells were isolated from the endometrium as previously described [32]. Both groups of cells were cultured in DMEM/F12 medium (Hyclone, Waltham, US) containing $10 \%$ FBS and 1\% Penicillin-Streptomycin at $37^{\circ} \mathrm{C}$ in a humidified environment with $5 \% \mathrm{CO}_{2}$. After co-culturing with HP-MSCs for $24 \mathrm{~h}, 48 \mathrm{~h}$, and $72 \mathrm{~h}$, respectively, the cells were used to measure EdU/Transwell/Western blot assay.

\section{In vivo tracing of CM-DiD/CM-DiR-labeled HP-MSCs}

The commercial cell membrane red fluorescent probe CM-DiD/CM-DiR (US Everbright ${ }^{\circledR}$ Inc, Jiangsu, China) was diluted with DMSO (Sigma, Darmstadt, Germany) according to the manufacturer's instructions to make a final concentration of $1 \mathrm{mM}$. HPMSCs at a density of $10^{6}$ cells $/ \mathrm{mL}$ were suspended in $5 \mathrm{~mL}$ PBS. $10 \mu \mathrm{L}$ CM-DiD or CM-DiR cell-labeling solution was then added at $37{ }^{\circ} \mathrm{C}$ for post-instillation tracking in utero. After $20 \mathrm{~min}$, the labelled cells were spun at $800 \times \mathrm{g}$ for $3 \mathrm{~min}$ and followed with washing twice with $5 \mathrm{~mL}$ PBS at $1000 \times \mathrm{g}$ for $5 \mathrm{~min}$ each. The CM-DiD and CM-DiR labelled HP-MSCs were then mixed with as-prepared HA hydrogel, respectively, to form two HP-MSCs-HA with different fluorescent labels. The mouse model was divided into two groups, as shown below, one group was injected with CM-DiR labelled HP-MSCs and HP-MSCs-HA for imaging, using an IVIS Spectrum to detect after transplantation for 1, 3, 7, 14, and 35 days, respectively. The other group was injected with CM-DiD label HP-MSCs and HP-MSCs-HA, which was used for the frozen section. Slides with $6 \mu \mathrm{m}$ thick (cutting with a CryoStar NX50, Thermo) were observed by an Olympus IX81-FV1000 fluorescence microscope.

CM-DiR labeled group:

Left uteri: instillation of $25 \mu \mathrm{L}$ HP-MSCs alone $\left(2 \times 10^{5}\right.$ per/uterus, coded as HP-MSCs $)$

Right uteri: instillation of $25 \mu \mathrm{L}$ HP-MSCs-HA

$\left(2 \times 10^{5} \mathrm{per} /\right.$ uterus, coded as HP-MSCs-HA)

CM-DiD labeled group:

Left uteri: instillation of $25 \mu \mathrm{L}$ HP-MSCs alone $\left(2 \times 10^{5}\right.$ per/uterus, coded as HP-MSCs $)$

Right uteri: instillation of $25 \mu \mathrm{L}$ HP-MSCs-HA $\left(2 \times 10^{5}\right.$ per/uterus, coded as HP-MSCs-HA $)$

\section{Transwell migration assay}

Human stromal cells or glandular cells were cultured in the upper plate compartment $(8-\mu \mathrm{m}, 24$-well insert, Corning, NY, USA), while the HP-MSCs were cultured in the lower chamber. They were then co-cultured at $37^{\circ} \mathrm{C}$ for $24 \mathrm{~h}, 48 \mathrm{~h}$, and $72 \mathrm{~h}$, respectively. The medium and cells were then removed from the upper chamber using cotton swabs with $1 \times \mathrm{PBS}$, while the migrated cells on the bottom surface of the membrane were fixed and stained with $0.5 \%$ crystal violet (Solarbio, Beijing, China) [33]. Cells from 5 random fields were counted using an inverted microscope (OLYMPUS BX61, Japan) with a magnification of $200 x$.

\section{EdU proliferation assay}

Human stromal cells or glandular cells were plated in 24-well plates and co-cultured with HP-MSCs in the upper insert (0.4- $\mu \mathrm{m}, 24$-well insert, Corning, NY, USA). After incubated for $24 \mathrm{~h}, 48 \mathrm{~h}$, and $72 \mathrm{~h}$, respectively, the transwell inserts loaded with HP-MSCs were removed, and cell proliferation activity was assessed using a commercially available EdU Assay Kit (RIBOBIO, Guangdong, China) according to the protocol provided. Cell proliferation was quantified by the incorporation of EdU into the newly synthesized DNA of replicating cells. The proliferated cells were dyed red, while the nuclei of all cells were dyed blue with DAPI. By counting EdU/DAPI ratio, cell proliferation ability can be assessed.

\section{Endothelial cell tube formation}

Cells were seeded in Matrigel-coated u-slides at a density of $1 \times 10^{4}$ cells per well (Ibidi, Germany) and incubated at $37^{\circ} \mathrm{C}$ for $4 \mathrm{~h}$. Images were acquired using an inverted microscope (OLYMPUS BX61, Japan). The results were quantified by counting the number of junctions, total tube length, and total branching length using ImageJ $1.52 \mathrm{k}$.

\section{Protein isolation and western blot analysis}

Proteins were extracted from the treated human endometrial stromal cells and glandular cells and then lysed by RIPA lysis buffer (Cell Signaling Technology, Boston, MA, USA) as previously described [23]. The protein concentration was detected using a bicinchoninic acid protein assay kit (Thermo Scientific, Waltham, USA). Proteins were denatured in a $5 \times$ SDS-PAGE loading buffer (CWBIO, Beijing, China). Then they were separated on sodium dodecyl sulfate-polyacrylamide gels and subsequently transferred onto nitrocellulose membranes. After being blocked with 5\% BSA (Albumin from bovine serum) in PBS, the membranes were incubated with primary and secondary antibodies. The immunoblots were 
washed with PBST (PBS with 0.1\% Tween-20). And then, the membranes were incubated overnight with primary antibodies at $4{ }^{\circ} \mathrm{C}$. After washing, secondary antibodies were added and incubated at room temperature for $1 \mathrm{~h}$ in the dark. Finally, the membranes were probed with an Odyssey CLx (LI-COR, USA). The signal intensity was calculated with ImageStudio (LI-COR, USA). Protein expression was normalized to $\beta$-Actin.

Rabbit monoclonal anti-p-JNK (9255), rabbit monoclonal anti-JNK (9252), rabbit monoclonal anti-p-Stat3 (9145), mouse monoclonal anti-Stat3 (9139), rabbit monoclonal anti-p-Erk1/2 (4370), rabbit monoclonal antiErk1/2 (4695), rabbit monoclonal anti-p-Jak2 (3771), rabbit monoclonal anti-Jak2 (3230), rabbit monoclonal anti-Stat5 (D3N2B), rabbit monoclonal anti-p-cFos (5348), rabbit monoclonal anti-c-Fos (2250), rabbit monoclonal anti-p-c-Jun (3270), and rabbit monoclonal anti-c-Jun (9165) were purchased from Cell Signaling Technology. Mouse monoclonal anti- $\beta$-Actin (sc-47778) was purchased from Santa Cruz. Rabbit monoclonal anti-VEGF (GTX102643) was purchased from Gene Tex. Goat anti-mouse fluorescent antibody (926-68020) and Goat anti-rabbit fluorescent antibody (926-32211) were purchased from LI-COR (USA).

\section{Establishment of the endometrium-injured mouse model} An 8-week-old female ICR mice of clean grade (SLAC company, Shanghai, China) were reared in the animal center under controlled conditions $\left(21-24{ }^{\circ} \mathrm{C}\right.$, relative humidity 40-60\%, $12 \mathrm{~h}$ light / $12 \mathrm{~h}$ dark cycle), with free access to food and water. To mimic endometrial injury in the clinical setting, we established a mouse model of thin endometrium by both mechanical and chemical injury at the estrous period. Briefly, the surgery involves mechanical intrauterine operation with a syringe contacting the uterine cavity and chemical injury by intrauterine perfusion with ethanol $(95 \%)[19,34,35]$. The mice were randomly assigned into five groups: sham-operated (PBS) group I, of which the uterine cavity was injected with 25 $\mu \mathrm{L}$ PBS and held for $3 \mathrm{~min}$; ethanol group II, for which $25 \mu \mathrm{L}$ 95\% ethanol was injected into the uterine cavity to induce damage for $3 \mathrm{~min}$ followed by $25 \mu \mathrm{L}$ PBS treatment; HA-treated group III, administration of $25 \mu \mathrm{L}$ $\mathrm{HA}$ after endometrium damage by $25 \mu \mathrm{L} 95 \%$ ethanol as described above; HP-MSCs-treated group IV, administration of $25 \mu \mathrm{L}$ HP-MSC ( $2 \times 10^{5}$ per/uterus) after inducing endometrium damage by $25 \mu \mathrm{L} 95 \%$ ethanol; and HPMSCs-HA-treated group V, administration of $25 \mu \mathrm{L} \mathrm{HP-}$ MSCs-HA $\left(2 \times 10^{5}\right.$ HP-MSCs per/uterus $)$ after inducing endometrium damage by $25 \mu \mathrm{L} 95 \%$ ethanol. After acclimation for 7 days, the mice were killed for further analyses. Additional file 1: Fig. S1 showed the construction and treatment procedure of the endometrium-injured mouse model in eight steps, which were briefly described as followings: I: mouse anesthesia; II: shaving the back of mouse; III: disinfecting exposed areas; IV: uteri exposure; V: instilling $25 \mu \mathrm{L}$ ethanol in the uterine cavity and holding $3 \mathrm{~min}$ to fully establish the model of thin endometrium; VI: intrauterine instillation of $25 \mu \mathrm{L}$ treating materials; VII: muscle suture; and VIII: closure of back skin incision.

\section{Histological analysis and immunohistochemistry}

Standard H\&E staining was used for murine endometrial assessment. 30 treated female mice (6 mice, 12 uteri in each group) were euthanized on day 7 after surgery. The isolated uteri were embedded in paraffin after fixing with $4 \%$ paraformaldehyde overnight. The wax blocks were cut into 3-4 $\mu \mathrm{m}$ thick and stained with Hematoxylin-Eosin staining by standard methods to observe the endometrial thickness and the number of glands. Light microscopy photographs (OLYMPUS VS200, Japan) and endometrial images were analyzed using the Application Program Image-Pro Plus (version 6.0). Endometrial area and perimeter were recorded to assess an average measurement of the endometrial thickness (mean endometrial thickness $=$ area/perimeter). Tissue sections were also labelled with Masson's trichrome to measure the degree of endometrial fibrosis by conventional methods. The area of fibrosis was quantified by measuring the area ratio between endometrial stromal fibrosis and the endometrial area using a quantitative image analysis system (Image-Pro Plus software; Media Cybernetics, Bethesda, MD). The immunofluorescence staining was conducted as previously described [32]. Sections were incubated with primary antibodies Ki67, a rabbit polyclonal primary antibody (ab16667; 1:200; Abcam, Cambridge, UK). The secondary antibody (GK600711; DakoCytomation, Glostrup, Denmark) was applied for $30 \mathrm{~min}$ at room temperature. The number of positive staining cells in the glands and stroma was semi-quantitatively scored by the immune response score (IRS) of two observers who did not know the source of the samples. The scoring criteria were the same as previously described [32].

\section{Fertility assessment}

Forty treated female mice ( 8 in each group) were mated with fertile males of the same age (female/male=1:1) 7 days after surgery. The female mice were checked for vaginal plugs the next morning to determine whether pregnancy had occurred. On the seventh day after the initial detection of vaginal plugs, the mice were sacrificed and the location and number of embryo implantation were recorded by photography. 


\section{Statistical analysis}

The collected data were analyzed using GraphPad Prism, ver. 8.4.0 software. All results were presented as mean \pm SEM. The software compared the means of samples using student's t-test between two groups and one-way analysis of variance (ANOVA) test among multiple groups. P-value $<0.05$ was considered statistically significant.

\section{Results}

\section{Fabrication and characterization of HA hydrogel}

As shown in Fig. 1A, the polymerizable GM-HA was prepared by the ring-opening reaction between $\mathrm{HA}$ and glycidyl methacrylate in PBS/DMF solution. Figure 1B shows the ${ }^{1} \mathrm{H}$-NMR spectrum of GM-HA with $\mathrm{D}_{2} \mathrm{O}$ as the solvent, of which the peaks of $\sim 5.72$ and $\sim 6.16 \mathrm{ppm}$ can be assigned to the vinyl protons of methacrylate. Besides, the peaks of $\sim 1.93$ and $\sim 2.00 \mathrm{ppm}$ represented the methyl protons of methacrylate and acetamide in GM-HA, respectively. The degree of methacrylation in GM-HA was estimated to be about $29 \%$ according to the ratio of integrated intensity between methacrylate protons and methyl protons in GM-HA acetamide. Figure 1C demonstrates the fabrication and instillation process of HP-MSCs-HA for endometrial therapy. The injectable HA hydrogel was prepared by the photocrosslinking of $1 \%$ GM-HA aqueous solution with $1 \%$ o photoinitiator under UV $(365 \mathrm{~nm})$ irradiation for $15 \mathrm{~min}$. The HP-MSCs were then encapsulated by HA hydrogel by uniformly mixing HP-MSCs with HA hydrogels, leading to the formation of HP-MSCs-HA. Figure 1D shows the FT-IR spectra of GM-HA and HA hydrogel. The absorption peak at $1630 \mathrm{~cm}^{-1}$ was attributed to the carbon-carbon double bond of methacrylate group. For HA hydrogel, a new absorption peak at $1250 \mathrm{~cm}^{-1}$ appeared, which can be assigned to the ether group next to the benzene ring of Irgacure 2959. After cross-linking reaction of the carbon-carbon double bond, the absorption intensity at $1630 \mathrm{~cm}^{-1}$ clearly decreased. The characteristic peaks of HA mainly contained the stretching vibrations of pyranose ring, glycosidic linkage, amide, ester, $-\mathrm{OH}$, and $-\mathrm{NH}$ groups. Among them, the peaks near $2900 \mathrm{~cm}^{-1}$ and $1400 \mathrm{~cm}^{-1}$ belonged to the stretching vibrations of $\mathrm{C}-\mathrm{H}$ and bending vibrations of $-\mathrm{CH}_{2}$, respectively. The peaks of the pyranose ring and glycosidic linkage can be observed around $1050 \mathrm{~cm}^{-1}$. The broad peak between 3250 to $3500 \mathrm{~cm}^{-1}$ was the typical $\mathrm{O}-\mathrm{H}$ and $\mathrm{N}-\mathrm{H}$ stretching vibrations. The peaks at $1550 \mathrm{~cm}^{-1}$ to $1700 \mathrm{~cm}^{-1}$ can be attributed to the amide and ester groups. The rheology measurements were performed to verify the formation of hydrogel. Figure $1 \mathrm{E}$ describes the storage modulus (G') and loss modulus (G") of HA hydrogel as a function of oscillation frequency at
$37{ }^{\circ} \mathrm{C}$, which reflected the elasticity and viscosity of the hydrogel, respectively. It is shown that G' of HA hydrogel was larger than the corresponding G" in the oscillation frequency range of 0.01 to $100 \mathrm{rad} / \mathrm{s}$, indicating that the elasticity of HA hydrogel dominates over its viscosity, which can guarantee the retention and coverage of HA hydrogel in the uterine cavity. The morphologies of HA and HA hydrogel were further observed by SEM. Figure $1 \mathrm{~F}$ indicates that HA did not have a homogeneous structure. However, the cross-linked HA hydrogel exhibited a porous and unbroken skeleton, as shown in Fig. 1G, which can thus facilitate the encapsulation and transportation of small molecules or cells.

\section{The retention time of HP-MSCs-HA in the endometrium}

To achieve optimization of therapeutic efficacy, HPMSCs-HA was fabricated in the present work to promote the enrichment and maximization of the retention of HPMSCs in the uterus. First, we studied the kinetics of the HP-MSCs being released from the cross-linked HA hydrogel as well as the retention time of HA hydrogel in murine uterine cavities. Unlike humans with solely one inverted pear shape uterus, there are two tubular uteri of mice, closely interlinked with the vagina. The endometriuminjured mouse model was constructed as described in the experimental section. Then, as shown in Fig. 2A, surgical instillation to the uterine cavity was adopted to provide stem cell in situ therapy. The left uteri of the endometriuminjured mouse model were then given with instillation of HP-MSCs, whereas the right uteri were injected with HPMSCs-HA. The HP-MSCs were labeled with two fluorescent-labelled fuels, CM-DiD and CM-DiR, respectively. CM-DiD labeling (ex/em: 644/663) was used to track HPMSCs by ex vivo frozen section, while CM-DiR labeling (ex/em: 748 /780) was suitable for detecting HP-MSCs by in vivo imaging. The in situ retention of CM-DiR labelled HP-MSCs was observed by an IVIS Spectrum Imaging System at different time points $(1,3,7,14,28$, and 35 days, respectively) after transplantation. Figure $2 \mathrm{~B}, \mathrm{C}$ illustrates HA hydrogel prolonged the retention time of HP-MSCs at every checkpoint and showed significant differences on day $1(20,120,000 \pm 4,640,589 \mathrm{p} / \mathrm{s}$ vs. $39,525,000 \pm 468,817 \mathrm{p} / \mathrm{s}$, $P<0.01)$. Besides, on day 7, the left uterus had few CM-DiR labelled HP-MSCs, while the right uterus injected with HPMSCs-HA still had prominent HP-MSCs retention, which indicated that the HP-MSCs could stay in the uterus of sexually mature mice for about two estrus cycles. An ex vivo frozen section of the uteri was conducted to confirm this further. As shown in Fig. 2D, the number of HP-MSCs decreased less slowly and exhibited better extension in the HP-MSCs-HA-treated group, consistent with the in vivo imaging results. Besides, these results also indicated that HP-MSCs could infiltrate and distribute in the functional 


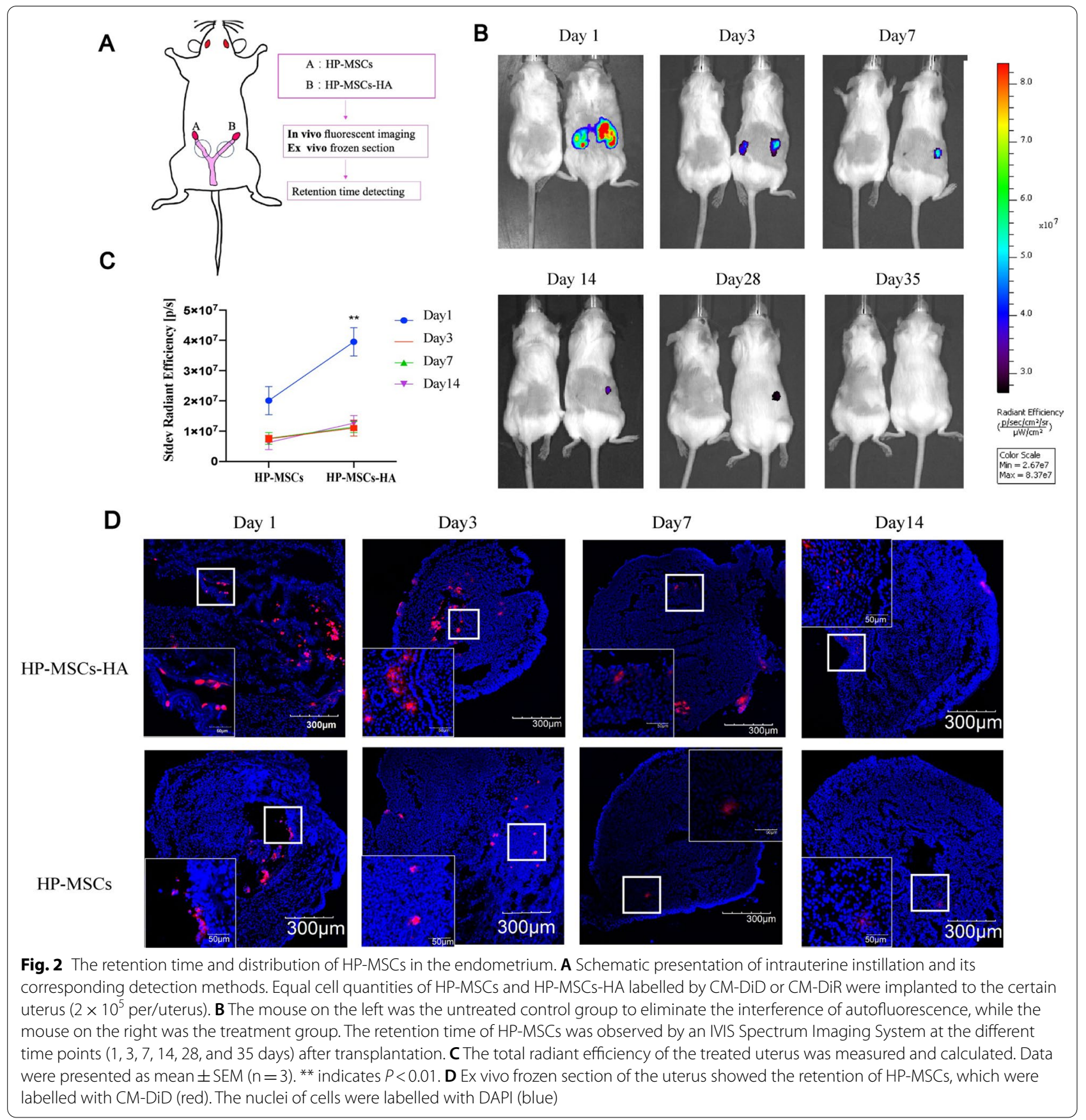

layer and basal layer of the endometrium, which was beneficial to the regeneration and repair of the endometrium.

\section{In vivo therapy of endometrium-injured mouse model with HP-MSCs-HA}

The in vivo endometrial repair effect of HP-MSCs-HA was thus investigated on the endometrium-injured mouse model established by ethanol perfusion to mimic endometrial injury in real clinical infertile patients. The in vivo embryo implantation rate and histological analysis of endometrium, including thickness and gland number, degree of fibrosis, and proliferation effect, were systematically studied.

Embryo implantation refers to the process of early embryo attachment and invasion of the endometrium. In humans, this process begins at the end of the first week after fertilization and endures until the second week of embryo development [36]. Successful embryo 
implantation requires a receptive endometrium, which allows the uterus to support the development of the embryo and fetus. Therefore, the status of the endometrium can be estimated by measuring the implantation rate of mouse embryos. As shown in Fig. 3A, the 6-8-week-old ICR mice were treated with in situ instillation of $25 \mu \mathrm{L}$ of $90 \%$ ethanol into the uterine to establish the endometrium-injured model. Correspondingly, a control mouse group injected with the same amount $(25 \mu \mathrm{L})$ of PBS was also set, which was marked as PBS, as shown in Fig. 3B. The endometrium-injured mice were then divided into four groups randomly and were subjected, respectively, to PBS, HA hydrogel, HP-MSCs, and HP-MSCs-HA injection into the injured uterine. The mice groups treated with PBS, HA hydrogel, HPMSCs, and HP-MSCs-HA were coded as Ethanol, HA, HP-MSCs, and HP-MSCs-HA, respectively (Fig. 3B). One week after surgery, some mice were mated with normal male mice to observe the embryo implantation rate. Figure $3 \mathrm{~B}, \mathrm{C}$ shows that the ethanol group exhibited a remarkable reduction in the number of implanted embryos compared to the PBS group. The average

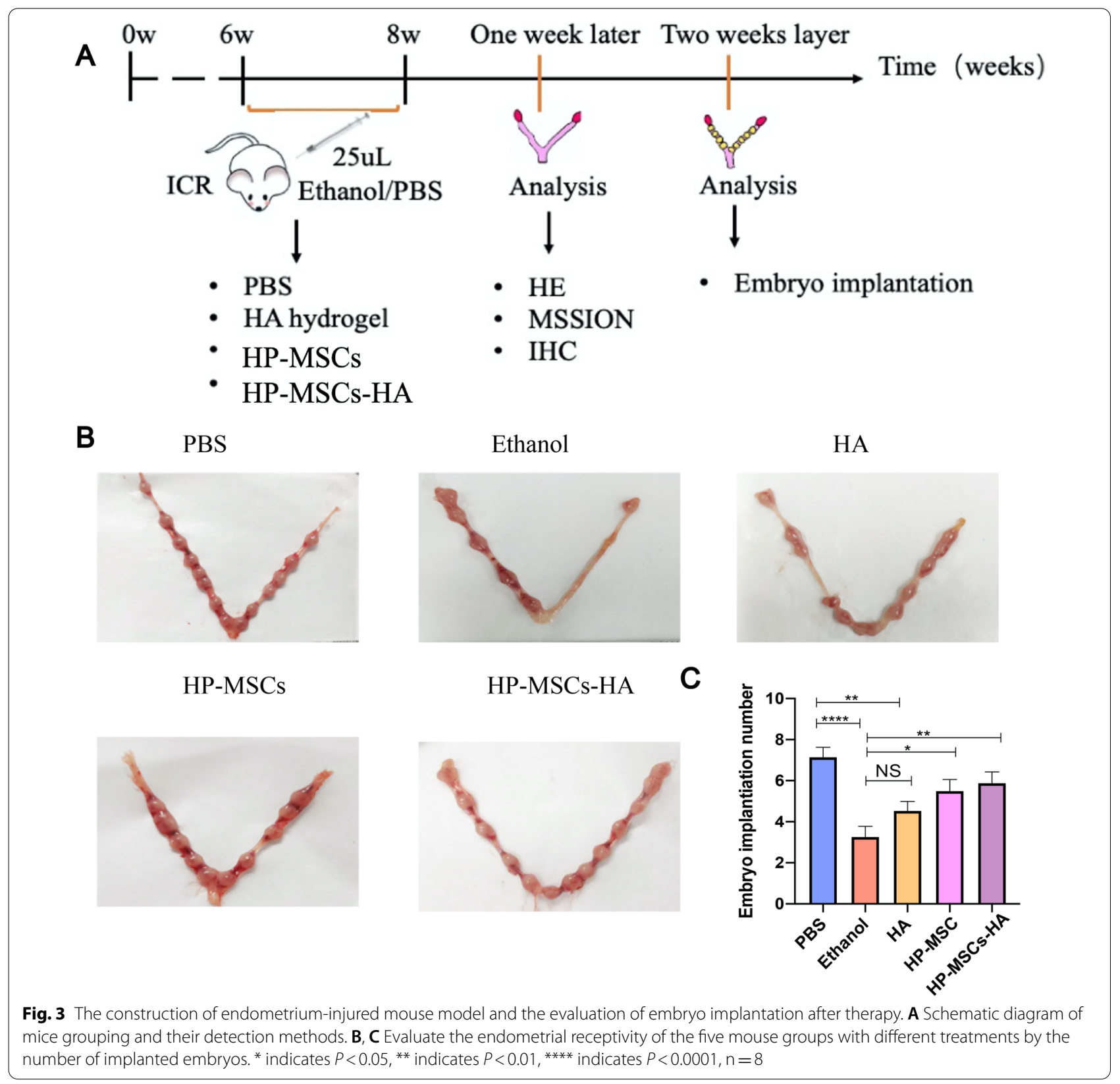


number of fetuses developed in the ethanol group was $3.273 \pm 0.506$, which is approximately half of the PBS group (7.154 \pm 0.478$)$, confirming the successful establishment of the endometrium-injured model. The HA group $(4.538 \pm 0.447)$ did not show the prominent difference in the number of fetuses as compared with that of the ethanol group, while the HP-MSC $(4.917 \pm 0.621)$ and HP-MSCs-HA group $(5.889 \pm 0.539)$ developed a significantly higher number of fetuses as compared with that of the ethanol group. Both the HP-MSCs group and HP-MSCs-HA group demonstrated significantly higher implantation rates compared to the ethanol group.

Maintaining sufficient endometrial thickness is a precondition for endometrial receptivity and implantation. Patients with thin endometrium have fewer glandular cells than the normal thickness group [6]. H\&E staining was applied to evaluate the endometrium thickness as well as the gland number in each group of mice one week after surgery. As shown in Fig. 4A, the ethanol group showed thinner endometrial thickness and fewer endometrial glandular cells than those of the PBS group. After treatment, the most effective endometrial regeneration was observed in the HP-MSCs-HA group, in which their endometrium presented a well-organized structure with epithelia and secretory glands. Besides, the thickness of the endometrial layers in the HP-MSCs-HA group was up to $292.3 \pm 19.14 \mu \mathrm{m}$, which was approximately twice as thick as that of the ethanol group $(171.3 \pm 14.59 \mu \mathrm{m})$ (Fig. 4E). As shown in Fig. 4F, the number of glandular cells was also significantly improved by HP-MSCs-HA treatment.

One of the commonly described causes of thin endometrium is Asherman syndrome (intrauterine adhesions), which is characterized by injury to the basal layer of the endometrium, leading to endometrial fibrosis [6, 37, 38]. Masson staining that can analyze the fibrous area and the collagen were used to evaluate intrauterine adhesions. The images in Fig. 4B, G revealed that the ethanol group presented higher fibrous tissue (blue) contents of $0.477 \pm 0.027$ than those of PBS group $(0.245 \pm 0.017)$, HA group $(0.374 \pm 0.027)$, HPMSCs group $(0.289 \pm 0.019)$, and HP-MSCs-HA groups $(0.279 \pm 0.016)$. The HP-MSCs and HP-MSCs-HA group exhibited significant therapeutic outcomes, in which the fibrosis area was not significantly different from that of the PBS group. Additionally, HA hydrogel alone can also restore fibrosis to some extent but is less effective than stem cell treatment.

The proliferation of endometrial cells can be assessed by immunohistochemical staining of Ki67, which can label the cells in the cell cycle. Figure $4 \mathrm{C}$ shows the proliferation of endometrial cells and stromal cells by the immunohistochemical staining of Ki67 for the five groups. As shown in Fig. 4H, the IRS scores of ki67 in PBS, ethanol, HA, HP-MSCs and HP-MSCs-HA groups were $4.743 \pm 0.745,2.008 \pm 0.306,3.201 \pm 0.427$, $4.104 \pm 0.369$, and $4.319 \pm 0.527$, respectively. The IRS of Ki67 in the ethanol group was significantly lower than that of the PBS group. Whereas, the HP-MSCs and HPMSCs-HA group presented an expression of Ki67 close to that of the PBS group.

Angiogenesis is necessary for the regeneration of endometrium and plays a crucial role in developing endometrial receptivity $[39,40]$. Miwa et al. suggested that reduced endometrial blood flow can result in poor endometrial growth, thus causing thin endometrium [41]. Such a phenomenon can be revealed by the decreased expression of endometrial vascular endothelial growth factor (VEGF): a critical factor in the regulation of endometrial angiogenesis [42]. As shown in Fig. 4D, I, the IRS scores of VEGF in PBS, Ethanol, HA, HP-MSCs and HP-MSCs-HA groups are 7.909 $\pm 0.3556,5.571 \pm 0.2542$, $6.208 \pm 0.3225, \quad 6.875 \pm 0.4443$, and $7.417 \pm 0.3981$, respectively. The IRS of VGEF in the ethanol group was significantly lower than that of the PBS group. Intriguingly, HP-MSCs-HA treatment could almost rescue VEGF expression, which indicated that HP-MSCs-HA treatment could facilitate angiogenesis in injured endometrium.

These in vivo experimental results indicated the safety and effectiveness of HP-MSCs-HA used for treating thin endometrium in the mouse model.

\section{Effects of HP-MSCs on the proliferation and migration of human endometrial stromal cell}

Based on the therapeutic results, further studies remain to uncover the underlying molecular mechanism. The stromal and glandular cells were thus isolated from the human endometrium to investigate the bioactive effects of HP-MSCs on them in vitro, as described in the experimental section. The human primary endometrial stromal and glandular cells were identified by immunohistochemical staining of CK7 and Vimentin, as shown in Additional file 1: Fig. S2. Besides, Fig. 5 illustrates the proliferation effect of HP-MSCs on human stromal cells. The human endometrial stromal cells were cultured without or with HP-MSCs for $24 \mathrm{~h}, 48 \mathrm{~h}$, and $72 \mathrm{~h}$, respectively, before EdU exposure. EdU/DAPI was the ratio of proliferating cells to total cells that can be used to evaluate cell proliferation. The proliferation rates of stromal cells without and with the presence of HP-MSCs were $14.34 \pm 1.492 \%$ vs. $23.64 \pm 1.795 \%$ at $24 \mathrm{~h}, 18.85 \pm 1.358 \%$ vs. $25.18 \pm 1.456 \%$ at $48 \mathrm{~h}$, and $25.86 \pm 4.657 \%$ vs. $45.5 \pm 4.442 \%$ at $72 \mathrm{~h}$, respectively (Fig. $5 \mathrm{~A}-\mathrm{C}, \mathrm{E}-\mathrm{G}$ ), confirming that the HP-MSCs significantly enhanced the proliferation ability of stromal cells. 


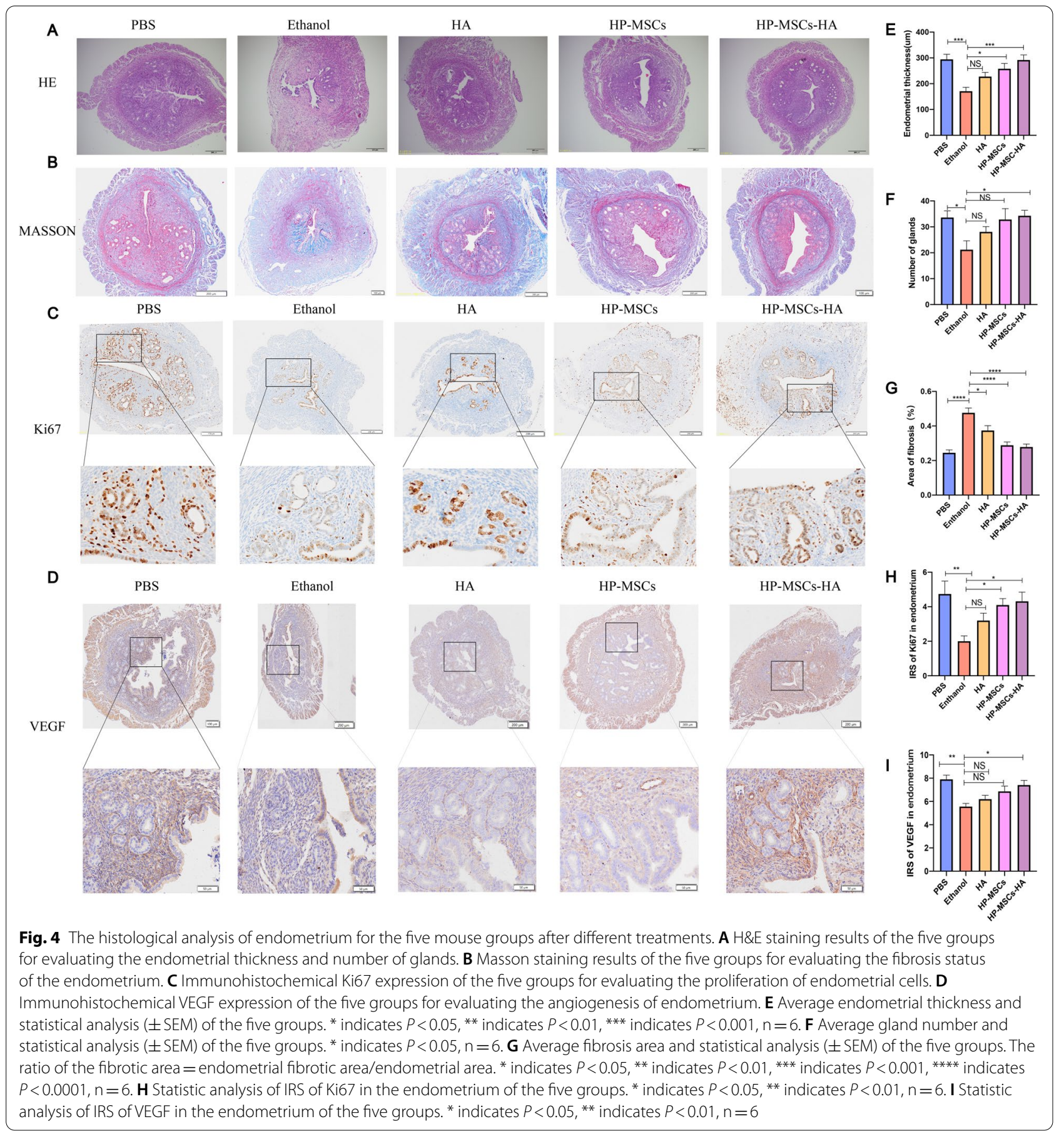

The effect of HP-MSCs on the migration of human endometrial stromal cells was also conducted. The stromal cells were cultured without (Ctr group) and with HP-MSCs (HP-MSCs group) for $24 \mathrm{~h}, 48 \mathrm{~h}$, and $72 \mathrm{~h}$, respectively, which were then analyzed by a transwell assay, as shown in Fig. 6A. The numbers of the migrated stromal cells in the HP-MSCs co-cultured group at $24 \mathrm{~h}$ and $48 \mathrm{~h}$ significantly exceeded that in the corresponding control group (Ctr) without HP-MSCs, as shown in Fig. 6B. However, at $72 \mathrm{~h}$, a minor difference in the number of migrated stromal cells can be observed between the Ctr and HP-MSCs groups. With quantification, the migration rate of stromal cells of the Ctr and HP-MSCs groups were significant as $11.6 \pm 1.691 \%$ 


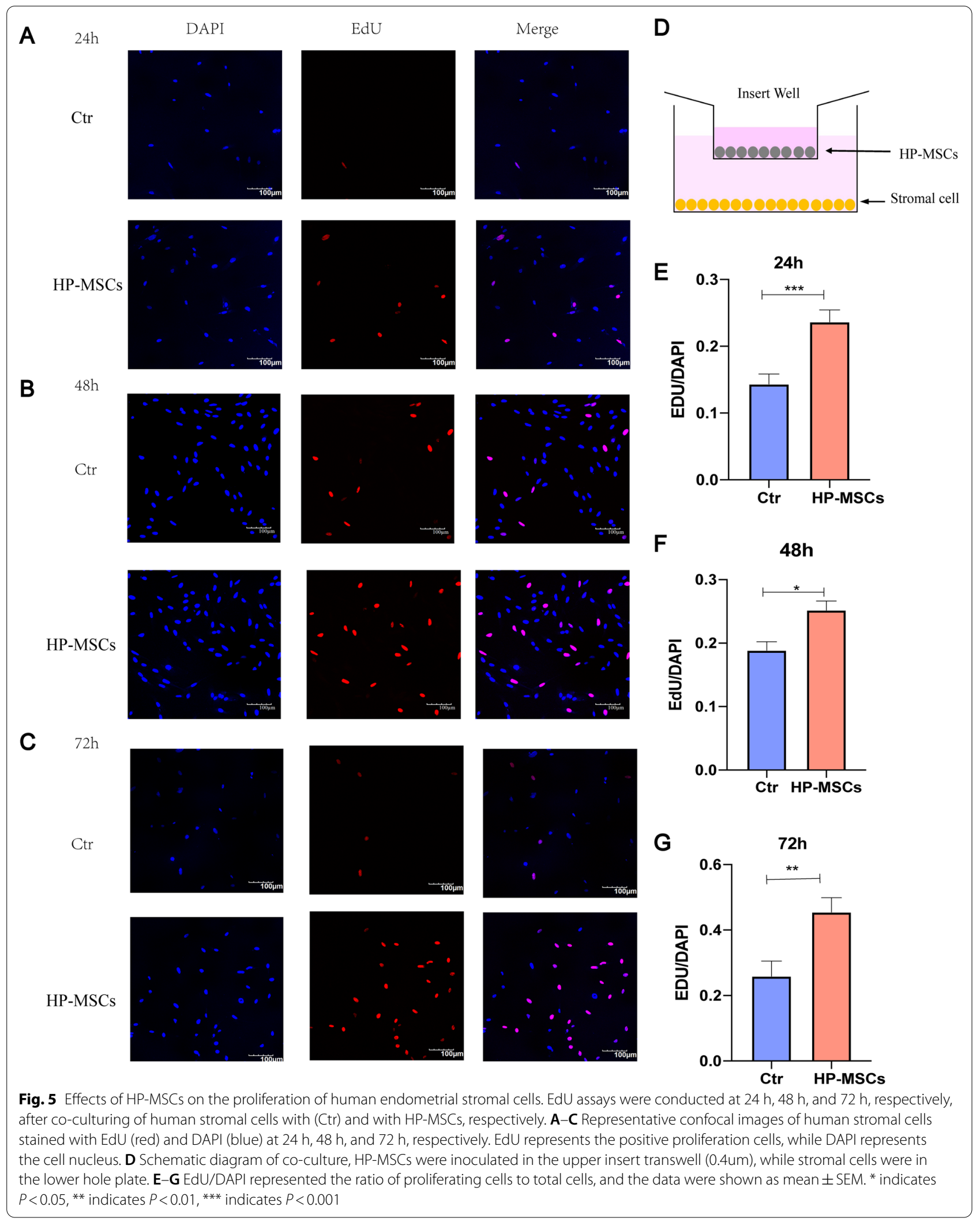



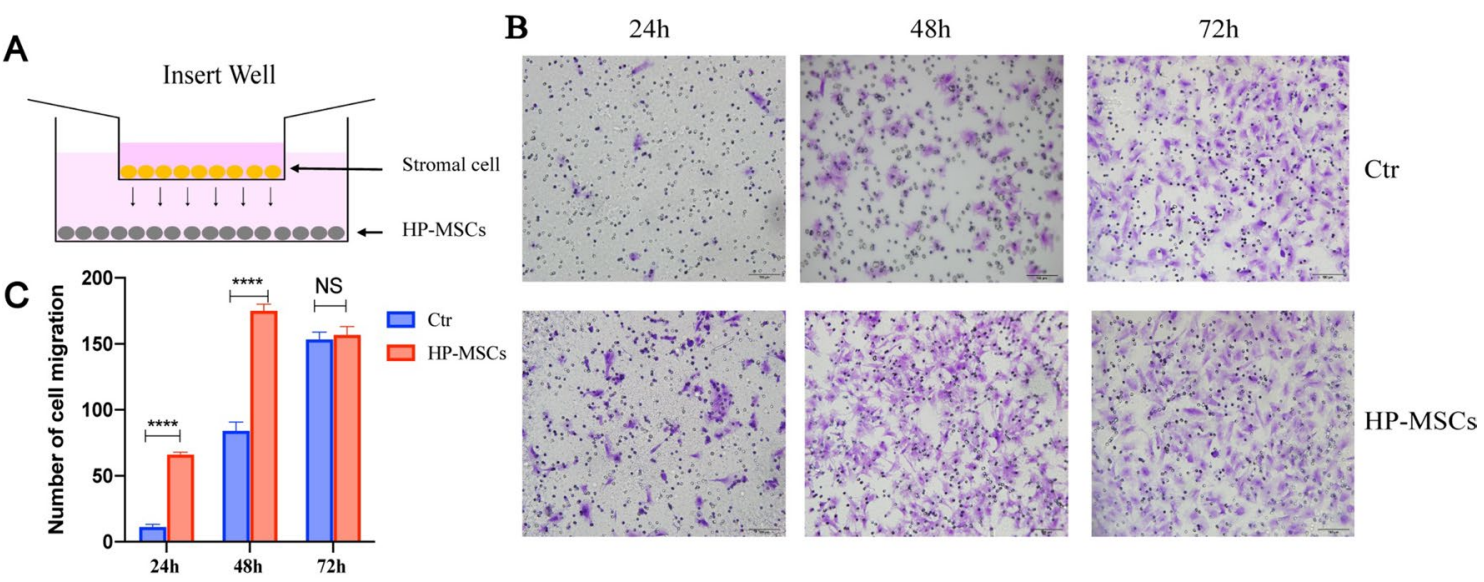

D
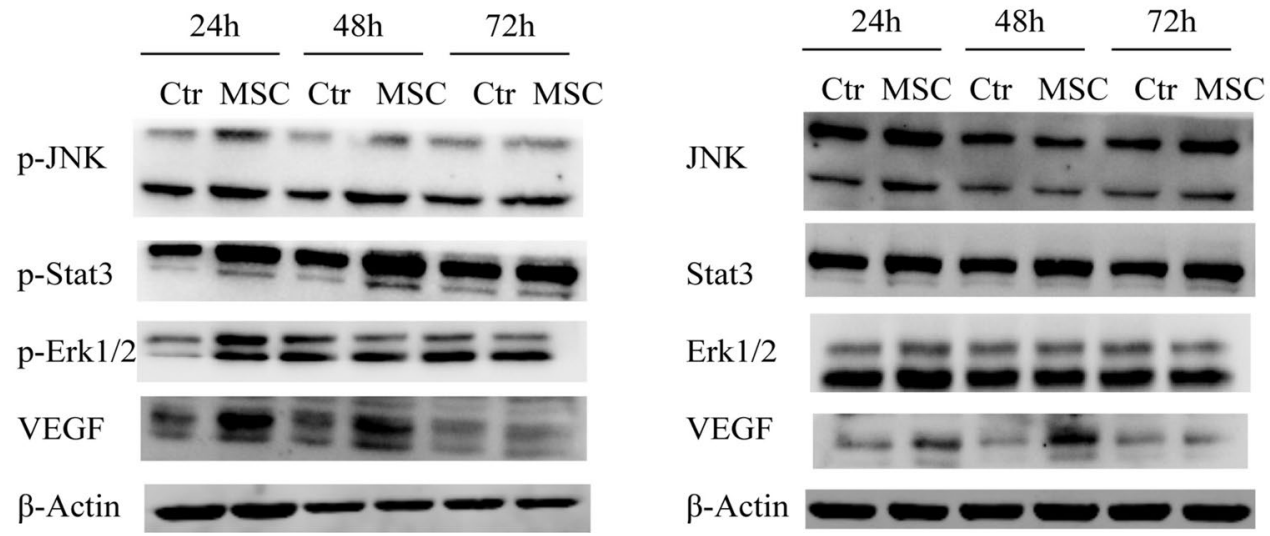

Fig. 6 Effect of HP-MSCs on the migration of human endometrial stromal cells. A Schematic of co-culturing the stromal cells with HP-MSCs. Stromal cells were inoculated in the upper insert transwell (8 um), while HP-MSCs were in the lower hole plate. B Transwell migration assay was conducted at $24 \mathrm{~h}, 48 \mathrm{~h}$, and $72 \mathrm{~h}$, respectively, after culturing without and with HP-MSCs, respectively. The migrated cells were stained with purple. C The average number of migrated stromal cells after culturing without or with HP-MSCs for $24 \mathrm{~h}, 48 \mathrm{~h}$, and $72 \mathrm{~h}$, respectively ( \pm SEM). * indicates $P<0.05$, ${ }^{* *}$ indicates $P<0.01,{ }^{* * *}$ indicates $P<0.001$. D p-JNK, p-Stat3, p-Erk1/2,VEGF, and corresponding total protein western blot analysis at $24 \mathrm{~h}$, $48 \mathrm{~h}$, and $72 \mathrm{~h}$, respectively, after culturing without and with HP-MSCs, respectively

vs. $66.4 \pm 1.435 \%$ at $24 \mathrm{~h}$ and $84.3 \pm 6.391 \%$ vs. $175.3 \pm 4.807 \%$ at $48 \mathrm{~h}$ (Fig. $6 \mathrm{C}$ ), indicating that HPMSCs not only benefited the proliferation of human endometrial stromal cells but also promoted their migration. To study the underlying mechanisms, we further determine which signaling pathway is involved in regulating the proliferation and migration of stromal cells. Figure 6D shows that co-culturing with HPMSCs can significantly promote VEGF expression and the phosphorylation level of JNK, Erk1/2, and Stat3 at $24 \mathrm{~h}$ in stromal cells. Besides, elevated expression of p-JNK, p-Stat3, and VEGF could be observed until $48 \mathrm{~h}$ compared to the control group. Hence with the above results, it can be concluded that co-culturing with HPMSCs exhibited beneficial effects on the proliferation and migration of human endometrial stromal cells via the JNK/Erk1/2-Stat3-VEGF pathway in vitro.

\section{Effect of HP-MSCs on the proliferation of human endometrial glandular cell}

In addition to stromal cells, endometrial glandular cells are the other essential component of the endometrium. Similarly, HP-MSCs were co-cultured with the glandular cells for $24 \mathrm{~h}, 48 \mathrm{~h}$, and $72 \mathrm{~h}$, respectively, and then examined by EdU assay (Fig. 7D). As shown in Fig. 7A$\mathrm{C}$, the proliferation rates of the HP-MSCs group and the basal medium group at $24 \mathrm{~h}, 48 \mathrm{~h}$, and $72 \mathrm{~h}$ were $2.842 \pm 0.463 \%$ vs. $4.278 \pm 0.463 \%, 5.203 \pm 0.559 \%$ vs. $5.561 \pm 0.988 \%, \quad 8.485 \pm 0.562 \% \quad$ vs. $\quad 10.94 \pm 1.488 \%$, respectively, which indicated that HP-MSCs could promote the proliferation of human endometrial glandular cells at $24 \mathrm{~h}$ (Fig. 7E). However, no significant differences were observed at $48 \mathrm{~h}$ and $72 \mathrm{~h}$ (Fig. 7F, G).

We further investigated the potential mechanisms of such proliferation enhancement via western blot. As shown in Fig. $7 \mathrm{H}$, the results of western blot validated 
that HP-MSCs can activate the phosphorylation of c-Fos and upregulate the expression of VEGF protein at $24 \mathrm{~h}$. Besides, elevated expression of p-Jak2 and p-Stat 5 were also observed after exposure to HP-MSCs for $24 \mathrm{~h}$. Taken together, these results proved that HP-MSCs co-culturing could improve the migration of human endometrial glandular cells via the Jak2-Stat 5 and c-Fos-VEGF pathway, providing favorable conditions for endometrial repair.

\section{Effect of HP-MSCs on the angiogenesis of HUVECs}

Previous in vivo studies had revealed the positive effects of HP-MSCs on angiogenesis by increasing the expression of VEGF. To further support the findings of increased VEGF expression that promote angiogenesis, we did the tube formation assay using human umbilical vein endothelial cells (HUVECs). After co-culturing with HP-MSCs for $24 \mathrm{~h}$, HUVECs were seeded in Matrigelcoated $\mathrm{u}$-slides at a density of $1 \times 10^{4}$ cells per well to test their angiogenic ability. As shown in Fig. 8, HP-MSCs co-culturing stimulated significant angiogenesis based on the length and branching length compared with the control (Ctr) group $(16,192 \pm 602.3$ vs. 19,125 \pm 507.5 , $16,064 \pm 646.7$ vs. $19,005 \pm 529.9$, respectively). This result further supported that HP-MSCs-HA treatment could promote angiogenesis in the endometrium.

\section{Discussion}

In this study, we demonstrated a novel strategy to improve the thickness of thin endometrium by HP-MSCs cross-linked with HA hydrogel. HP-MSCs-HA could retain in the endometrium to promote proliferation, migration of stromal cells and glandular cells, as well as angiogenesis, thereby improving embryo implantation rates.

Recent studies have shown that MSCs could serve as a therapeutic agent for thin endometrium caused by endometrial injury $[15,16]$. Though MSCs can be found in bone marrow, umbilical cord, fat tissue, and amniotic membrane, they are difficult to obtain for large-scale clinical applications owing to the limited sources and invasively collecting methods. HP-MSCs represent an emerging alternative source for tissue regeneration. HPMSCs are advantageous over other MSCs for various reasons, such as their robust expansion ability, superior safety profile, and extensive sources. Noticeably, HPMSCs can be directly applied to mouse models without immune response due to the low immunogenicity [4345]. These advantages of HP-MSCs make them the ideal source for cell therapy. Interestingly, HP-MSCs are also found to improve angiogenesis, trigger regeneration of damaged organs [35]. These suggest that HP-MSCs based therapy is a potential therapeutic approach.

Mesh-like HA hydrogel can provide structural and mechanical support for HP-MSCs, and improve their retention time and therapeutic effects. Moreover, HA hydrogel is safe for mice and humans since it can be decomposed by hyaluronidase in the endometrium. In our study, HP-MSCs-HA could infiltrate and distribute both in functional layer and basal layer of endometrium, and retain longer than HP-MSCs. This effect is very likely due to the gradual release of HP-MSCs from the hydrogel, which indicated the great potential of HA hydrogel as an intrauterine controlled-release delivery system. Based on our study, 3D HA hydrogel facilitated more HP-MSCs survived and retained in the uterus to secrete more growth factors, which contributed to cell proliferation and angiogenesis within the endometrium. This paracrine effect may play a vital role in restoring thin endometrium, including the elevated endometrial thickness and embryo implantation rate. We further confirmed the effects of following treatments (HA group, HP-MSCs group, and HP-MSCs-HA group) on endometrial injury repair in the mouse model. There were no significant differences between the HA group and ethanol group in embryo implantation rate, gland number, endometrial thickness, and the IRS score of Ki67 and VEGF. Besides, no significant differences were observed between the HP-MSCs group and the ethanol group in increasing the number of glands and VEGF expression. Notably, HPMSCs-HA treatment showed significance in all detected indexes compared with the ethanol group. Therefore, those results revealed the necessity of combining HPMSCs with HA hydrogel in treatment of thin endometrium, which could help improve patient outcomes. Besides, Hooker et al. recently found that HA hydrogel therapy seems to improve fertility and reproductive outcomes in women, which indicated the extra beneficial characteristic of HA hydrogel on endometrial repair [10, 11]. Based on our study, HA combined with HP-MSCs therapy may be a promising treatment for patients with thin endometrium.

Cell proliferation, differentiation, angiogenesis, and migration are essential in re-epithelialization of the

(See figure on next page.)

Fig. 7 Effect of HP-MSCs on the proliferation of human endometrial glandular cells. A-C EdU assays were conducted after co-culturing the glandular cells without and with HP-MSCs for 24 h, 48 h, 72 h, respectively. Representative confocal images of the glandular cells stained with EdU (red) and DAPI (blue). D Schematic of co-culturing the glandular cells with HP-MSCs. HP-MSCs were inoculated in the upper insert transwell (0.4um), while the glandular cells were in the bottom plate. E-G Average EdU/DAPI ratio ( \pm SEM). ${ }^{*}$ indicates $P<0.05$. H p-Jak2, p-Stat5, p-c-Fos, p-c-Jun, VEGF, and corresponding total protein western blot analysis at $24 \mathrm{~h}, 48 \mathrm{~h}$, and $72 \mathrm{~h}$, after culturing without and with HP-MSCs, respectively 


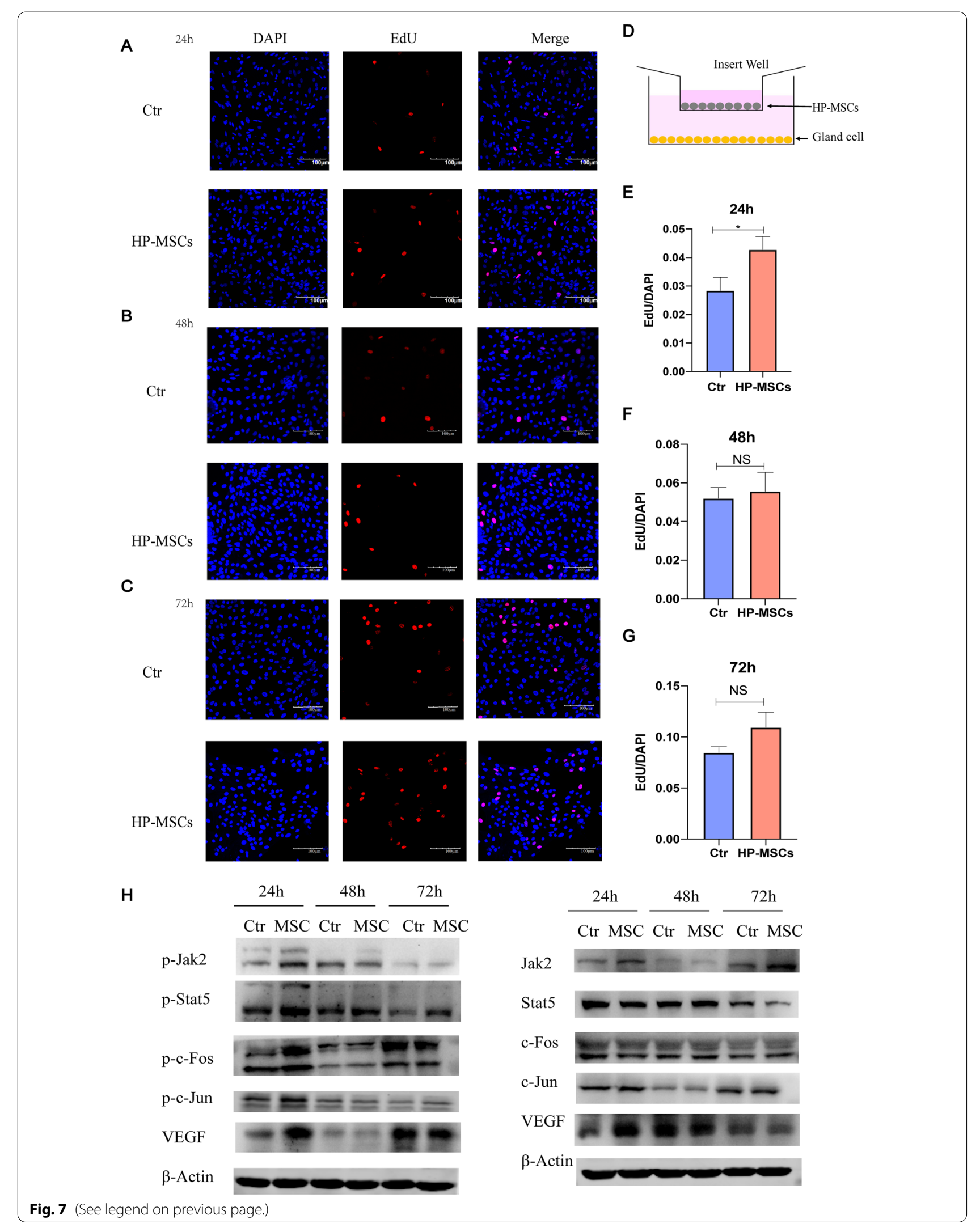



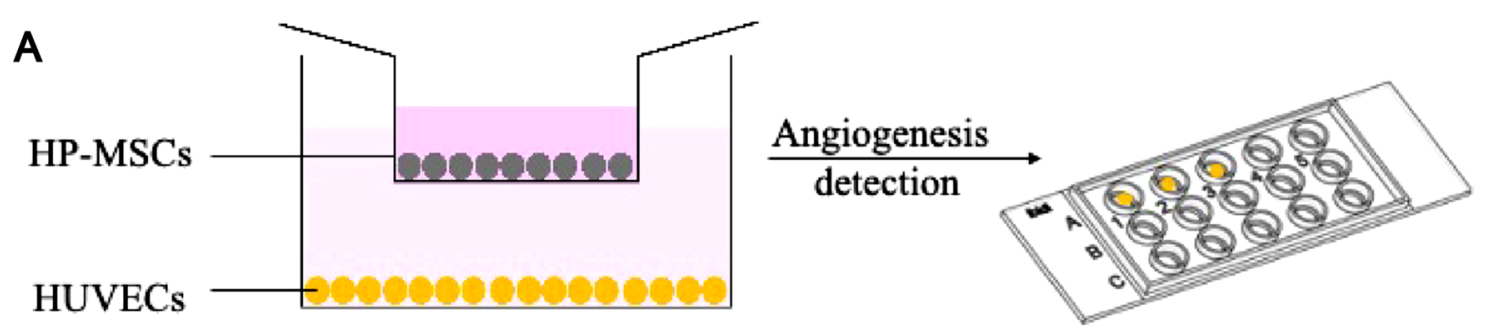

B

Ctr

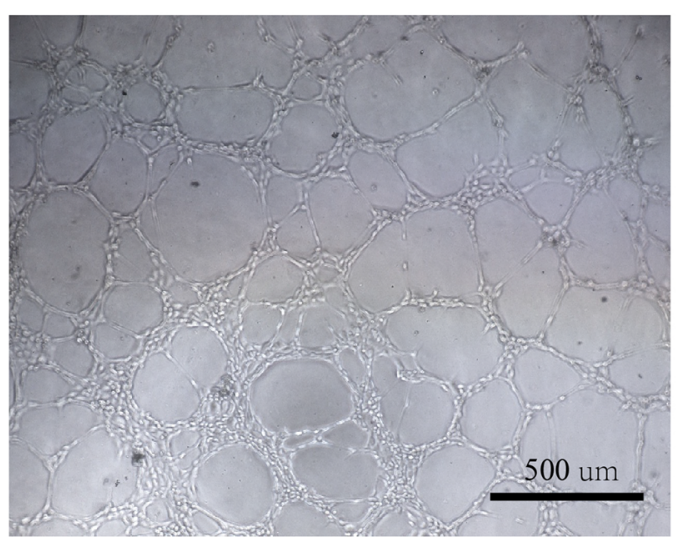

HP-MSCs

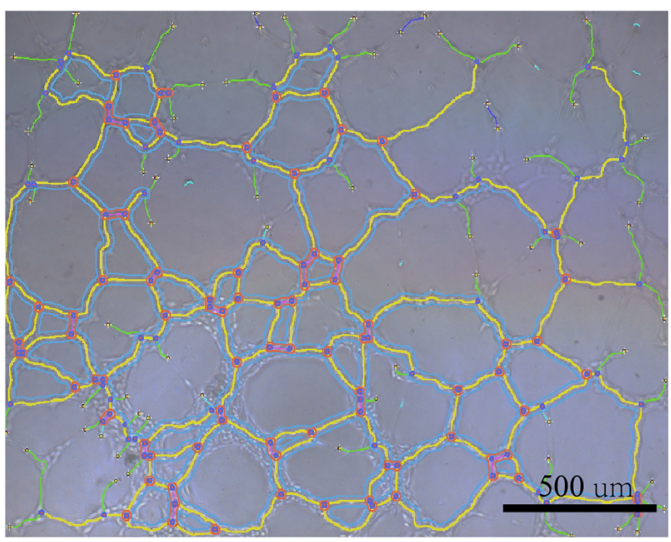

C

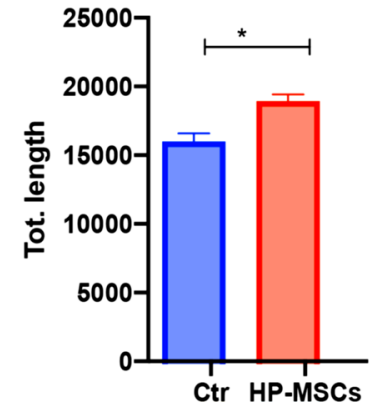

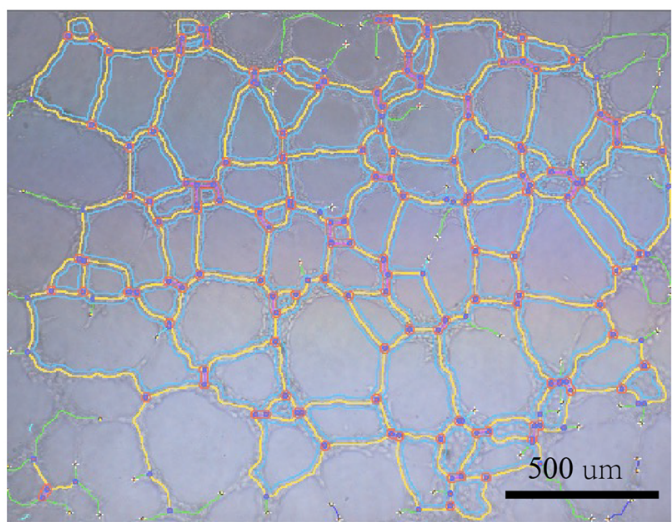

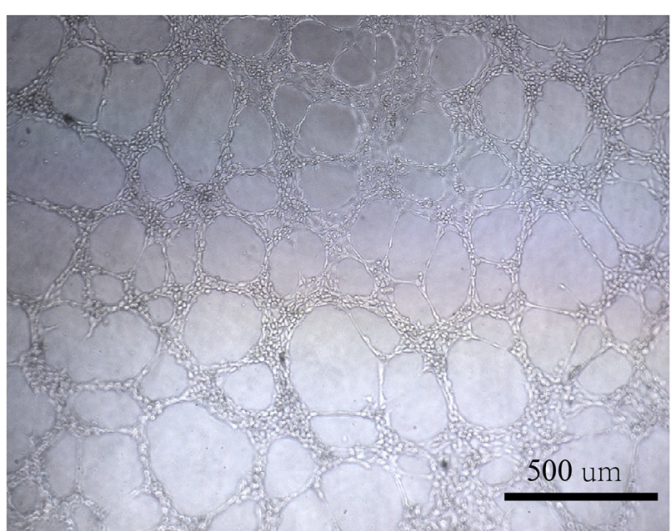

D

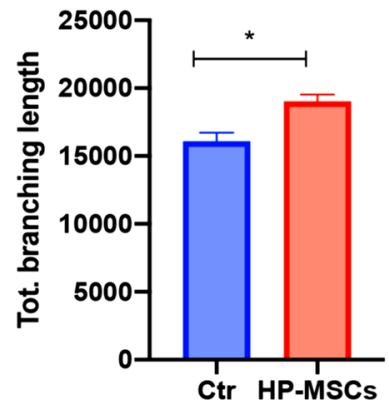

Fig. 8 HUVECS angiogenesis assay. A Schematic of co-culturing the HP-MSCs with HUVECs. After $24 \mathrm{~h}$ co-culturing with HP-MSCs, HUVECS were seeded in Matrigel-coated u-slides to conduct tube formation assay. B Representative tube formation images of Ctr and HP-MSCs group. C, D Quantitative assay of tube formation assay and data were expressed as mean \pm SEM. * indicates $P<0.05$ 
injured endometrium [46]. The ERK1/2 and JNK are two parallel MAPK signaling pathways in response to diverse extracellular stimuli, and they are involved in cell growth, differentiation, apoptosis, and inflammatory response effects $[47,48]$. In our study, the protein levels of p-JNK, p-ERK1/2, p-STAT3, and VEGF were remarkably increased in HP-MSCs-treated endometrial stromal cells, which may partially explain the proliferation and migration-promoting effects of HP-MSCs on stromal cells. Consistent with our findings, evidence has shown that activating the JNK/Erk1/2-Stat3-VEGF pathway can promote the development of endometrial cells and likely enhance the uterine capacity $[49,50]$. Jak2/Stat5 and c-Jun/c-Fos pathway play an important role in cell proliferation and migration. In our study, Jak2-Stat5 and c-Fos-VEGF pathways were upregulated in glandular cells when co-cultured with HP-MSCs, which may account for the increase of gland number in HP-MSCs treated group.

\section{Conclusions}

In this study, HP-MSCs-HA were successfully prepared for the treatment of endometrial injury. HP-MSCsHA exhibited a prolonged retention time in mouse uterus in contrast to HP-MSCs instillation alone. The in vivo therapeutic outcomes of endometrium-injured mouse models proved that HP-MSCs-HA could rescue the injured endometrium in mice via increasing the endometrial thickness and gland number, decreasing the fibrous area, promoting angiogenesis, and thus improving the implantation rate. The in vitro results suggested that HP-MSCs could promote the proliferation of human endometrial stromal cells by activating the JNK/Erk1/2-Stat3-VEGF pathway, and enhance the proliferation and migration of glandular cells via Jak2-Stat5 and c-Fos-VEGF pathway. Besides, HPMSCs could also promote the angiogenesis of endothelial cells, which was consistent with previous in vivo results. Overall, our study provides theoretical and experimental foundations for the clinical treatment of thin endometrium using HP-MSCs-HA.

\footnotetext{
Abbreviations

ART: Assisted reproductive technologies; BM-MSCs: Bone marrow-derived mesenchymal stem cells; FBS: Fetal bovine serum; FT-IR: Fourier transform infrared; GMA: Glycidyl methacrylate; HA: Hyaluronic acid; HA hydrogel: Hyaluronic acid hydrogel; HCG: Human chorionic gonadotropin; HP-MSCs: Human placenta-derived mesenchymal stem cells; HP-MSCs-HA: HP-MSCs encapsulated within HA hydrogels; HUVECs: Human umbilical vein endothelial cells; Jak2: Janus Kinase 2; MSCs: Mesenchymal stem cells; PBS: Phosphate buffer saline; SEM: Scanning electron microscopy; Stat3: Signal transducer and activator of transcription 3; Stat5: Signal transducer and activator of transcription 5; TEA: Triethylamine; UC-MSCs: Umbilical cord-derived MSCs.
}

\section{Supplementary Information}

The online version contains supplementary material available at https://doi. org/10.1186/s13287-022-02717-2.

Additional file 1: Fig. S1. The construction process of the endometriuminjured mouse model. I: mouse anesthesia; ll: shaving the back of mouse; III: disinfecting exposed areas; IV: uteri exposure; V: instilling $25 \mu \mathrm{L}$ ethanol in the uterine cavity and holding 3 min to fully establish the model of thin endometrium; $\mathrm{VI}$ : intrauterine instillation of $25 \mu \mathrm{L}$ treating materials; VII: muscle suture; and VIII: closure of back skin incision. Fig. S2. Identification of human primary endometrial glandular cells and stromal cells by immunohistochemical staining of CK7 and Vimentin, respectively.

\section{Acknowledgements}

We thanked the College of Life Sciences-iCell Biotechnology Regenerative Biomedicine Laboratory, Zhejiang University, for kindly providing us with identified HP-MSCs.

\section{Authors' contributions}

The manuscript was written through the contributions of all authors. ZD and $D B$ designed, organized, and instructed the study. ZD, DB, LY, DS, and YX contributed to study concept and design; $L Y, Y X, L J, C R, W F$, and $C J$ collected the human endometrial samples; $L Y, D S, Y X, L, Z Y, Y Y$, and NF performed the experiments; $L Y, D S, Y X$, and $L J$ analyzed and interpreted the results; $L Y, D S, T M$, WS, and $Y X$ drafted the manuscript; $Z D, D B, L Y, D S$, and $Y X$ revised the manuscript. All authors read and approved the final manuscript.

\section{Funding}

This work was supported by the National Key Research and Development Program of China (2018YFC1005003), Zhejiang Provincial Key Research and Development Program (No. 2021C03098), the National Natural Science Foundation of China (No. 81771535 and 21875214), Zhejiang Provincial Key Medical Technology Program (WKJ-ZJ-1826), and the second level of the 2016 Zhejiang Province 151 Talent Project.

\section{Availability of data and materials}

The datasets used and/or analyzed during the current study are available from the corresponding author on reasonable request.

\section{Declarations}

\section{Ethics approval and consent to participate}

The research protocol was approved by the Ethics Committee of the Women's Hospital of Zhejiang University, China. Written informed consents were obtained from all participants before tissue collection. All animal research, feeding, processing, stem cell instillation, sample collection, and experimental procedures were carried out following the principles and procedures. We confirmed that the human and animal studies in our experiments were carried out under the relevant guidelines and regulations approved by the Women's Hospital of Zhejiang University (IRB-20210054-SC) and Laboratory Animal Center of Zhejiang University (ZJU20210088), China.

\section{Consent for publication}

Not applicable.

\section{Competing interests}

The authors declare that they have no competing interests.

\section{Author details \\ ${ }^{1}$ Key Laboratory of Women's Reproductive Health of Zhejiang Province and Department of Reproductive Endocrinology, Women's Hospital, Zhejiang University School of Medicine, Hangzhou 310006, Zhejiang, China. ${ }^{2}$ MOE Key Laboratory of Macromolecular Synthesis and Functionalization, Department of Polymer Science and Engineering, Zhejiang University, Hangzhou 310027,}


China. ${ }^{3}$ Key Laboratory of Reproductive Genetics (Ministry of Education) and Department of Reproductive Endocrinology, Women's Hospital, Zhejiang University School of Medicine, Hangzhou 310006, Zhejiang, China.

Received: 21 July 2021 Accepted: 4 January 2022

Published online: 08 February 2022

\section{References}

1. Ombelet W, Cooke I, Dyer S, Serour G, Devroey P. Infertility and the provision of infertility medical services in developing countries. Hum Reprod Update. 2008;14(6):605-21.

2. Carson S, Kallen A. Diagnosis and Management of Infertility: a Review. JAMA. 2021;326(1):65-76.

3. Lédée-Bataille N, Laprée-Delage G, Taupin JL, Dubanchet S, Frydman R, Chaouat G. Concentration of leukaemia inhibitory factor (LIF) in uterine flushing fluid is highly predictive of embryo implantation. Hum Reprod. 2002;17(1):213-8.

4. Deans R, Abbott J. Review of intrauterine adhesions. J Minim Invasive Gynecol. 2010;17(5):555-69.

5. Cenksoy P, Ficicioglu C, Yıldırım G, Yesiladali M. Hysteroscopic findings in women with recurrent IVF failures and the effect of correction of hysteroscopic findings on subsequent pregnancy rates. Arch Gynecol Obstet. 2013;287(2):357-60

6. Liu K, Hartman M, Hartman A. Management of thin endometrium in assisted reproduction: a clinical practice guideline from the Canadian Fertility and Andrology Society. Reprod Biomed Online. 2019;39(1):49-62.

7. El-Toukhy T, Coomarasamy A, Khairy M, Sunkara K, Seed P, Khalaf Y, Braude $P$. The relationship between endometrial thickness and outcome of medicated frozen embryo replacement cycles. Fertil Steril. 2008:89(4):832-9.

8. Tan S-Y, Hang F, Purvarshi G, Li M-Q, Meng D-H, Huang L-L. Decreased endometrial vascularity and receptivity in unexplained recurrent miscarriage patients during midluteal and early pregnancy phases. Taiwan J Obstet Gynecol. 2015:54(5):522-6.

9. Rinaldi L, Lisi F, Floccari A, Lisi R, Pepe G, Fishel S. Endometrial thickness as a predictor of pregnancy after in-vitro fertilization but not after intracytoplasmic sperm injection. Hum Reprod. 1996;11(7):1538-41.

10. Momeni M, Rahbar MH, Kovanci E. A meta-analysis of the relationship between endometrial thickness and outcome of in vitro fertilization cycles. J Hum Reprod Sci. 2011;4(3):130-7.

11. Noyes N, Liu HC, Sultan K, Schattman G, Rosenwaks Z. Endometrial thickness appears to be a significant factor in embryo implantation in in-vitro fertilization. Hum Reprod. 1995:10(4):919-22.

12. Richter KS, Bugge KR, Bromer JG, Levy MJ. Relationship between endometrial thickness and embryo implantation, based on 1,294 cycles of in vitro fertilization with transfer of two blastocyst-stage embryos. Fertil Steril. 2007:87(1):53-9.

13. Liu KE, Hartman M, Hartman A, Luo ZC, Mahutte N. The impact of a thin endometrial lining on fresh and frozen-thaw IVF outcomes: an analysis of over 40000 embryo transfers. Hum Reprod. 2018;33(10):1883-8.

14. Lebovitz O, Orvieto R. Treating patients with "thin" endometrium - an ongoing challenge. Gynecol Endocrinol. 2014;30(6):409-14

15. Yang H, Wu S, Feng R, Huang J, Liu L, Liu F, Chen Y. Vitamin C plus hydrogel facilitates bone marrow stromal cell-mediated endometrium regeneration in rats. Stem Cell Res Ther. 2017;8(1):267-267.

16. Zhang L, Li Y, Guan C-Y, Tian S, Lv X-D, Li J-H, Ma X, Xia H-F. Therapeutic effect of human umbilical cord-derived mesenchymal stem cells on injured rat endometrium during its chronic phase. Stem Cell Res Ther. 2018;9(1):36-36.

17. Andrzejewska A, Lukomska B, Janowski M. Concise review: mesenchymal stem cells: from roots to boost. Stem Cells. 2019:37(7):855-64.

18. Samsonraj RM, Raghunath M, Nurcombe V, Hui JH, van Wijnen AJ, Cool SM. Concise review: multifaceted characterization of human mesenchymal stem cells for use in regenerative medicine. Stem Cells Transl Med. 2017:6(12):2173-85

19. Xia L, Meng Q, Xi J, Han Q, Cheng J, Shen J, Xia Y, Shi L. The synergistic effect of electroacupuncture and bone mesenchymal stem cell transplantation on repairing thin endometrial injury in rats. Stem Cell Res Ther. 2019:10(1):244.
20. Park S, Koh SE, Hur CY, Lee WD, Lim J, Lee YJ Comparison of human first and third trimester placental mesenchymal stem cell. Cell Biol Int. 2013:37(3):242-9.

21. Zhu SF, Zhong ZN, Fu XF, Peng DX, Lu GH, Li WH, Xu HY, Hu HB, He JM, Su $W Y$, et al. Comparison of cell proliferation, apoptosis, cellular morphology and ultrastructure between human umbilical cord and placenta-derived mesenchymal stem cells. Neurosci Lett. 2013:541:77-82.

22. Feng X, Liu J, Xu Y, Zhu J, Chen W, Feng B, Pan Q, Yu J, Shi X, Yang J, et al. Molecular mechanism underlying the difference in proliferation between placenta-derived and umbilical cord-derived mesenchymal stem cells. J Cell Physiol. 2020;235(10):6779-93.

23. Weissmann B. The transglycosylative action of testicular hyaluronidase. J Biol Chem. 1955;216(2):783-94.

24. Liu F, Hu S, Yang H, Li Z, Huang K, Su T, Wang S, Cheng K. Hyaluronic acid hydrogel integrated with mesenchymal stem cell-secretome to treat endometrial injury in a rat model of Asherman's syndrome. Adv Healthcare Mater. 2019;8(14):e1900411.

25. Liu F, Hu S, Wang S, Cheng K. Cell and biomaterial-based approaches to uterus regeneration. Regener Biomater. 2019;6(3):141-8.

26. Lin Y, Dong S, Zhao W, Hu K-L, Liu J, Wang S, Tu M, Du B, Zhang D. Application of hydrogel-based delivery system in endometrial repair. ACS Appl Bio Mater. 2020;3(11):7278-90.

27. Kim YY, Park KH, Kim YJ, Kim MS, Liu HC, Rosenwaks Z, Ku SY. Synergistic regenerative effects of functionalized endometrial stromal cells with hyaluronic acid hydrogel in a murine model of uterine damage. Acta Biomater. 2019:89:139-51.

28. Zhu R, Huang YH, Tao Y, Wang SC, Sun C, Piao HL, Wang XQ, Du MR, Li DJ. Hyaluronan upregulates growth and invasion of trophoblasts in an autocrine manner via PI3K/AKT and MAPK/ERK1/2 pathways in early human pregnancy. Placenta. 2013;34(9):784-91.

29. Spencer T, Hayashi K, Hu J, Carpenter K. Comparative developmental biology of the mammalian uterus. Curr Top Dev Biol. 2005;68:85-122.

30. Zhang K, Chen X, Li H, Feng G, Nie Y, Wei Y, Li N, Han Z, Han Z, Kong D, et al. A nitric oxide-releasing hydrogel for enhancing the therapeutic effects of mesenchymal stem cell therapy for hindlimb ischemia. Acta Biomater. 2020:113:289-304.

31. Yen B, Hwa H, Hsu P, Chen P, Wang L, Jiang S, Liu K, Sytwu H, Yen M. HLA-G expression in human mesenchymal stem cells (MSCs) is related to unique methylation pattern in the proximal promoter as well as gene body DNA. Int J Mol Sci. 2020;21(14):5075. https://doi.org/10.3390/ijms21145075.

32. Liu J, Ying Y, Wang S, Li J, Xu J, LV P, Chen J, Zhou C, Liu Y, Wu Y, et al. The effects and mechanisms of GM-CSF on endometrial regeneration. Cytokine. 2020;125:154850.

33. Liu Y, Zhang $X$, Sun T, Jiang J, Li Y, Chen M, Wei Z, Jiang W, Zhou L. Knockdown of Golgi phosphoprotein 2 inhibits hepatocellular carcinoma cell proliferation and motility. Oncotarget. 2016;7(16):21404-15.

34. Li J, Huang B, Dong L, Zhong Y, Huang Z. WJ-MSCs intervention may relieve intrauterine adhesions in female rats via TGF- $\beta 1$-mediated Rho/ ROCK signaling inhibition. Mol Med Rep. 2021:23(1):15.

35. Xie Y, Tian Z, Qi Q, Li Z, Bi Y, Qin A, Yang Y. The therapeutic effects and underlying mechanisms of the intrauterine perfusion of granulocyte colony-stimulating factor on a thin-endometrium rat model. Life Sci. 2020:260:118439.

36. Wilcox AJ, Baird DD, Weinberg CR. Time of implantation of the conceptus and loss of pregnancy. N Engl J Med. 1999:340(23):1796-9.

37. Zupi E, Centini G, Lazzeri L. Asherman syndrome: an unsolved clinical definition and management. Fertil Steril. 2015;104(6):1380-1.

38. Yu D, Wong Y, Cheong Y, Xia E, Li T. Asherman syndrome-one century later. Fertil Steril. 2008;89(4):759-79.

39. Smith S. Angiogenesis, vascular endothelial growth factor and the endometrium. Hum Reprod Update. 1998;4(5):509-19.

40. Smith SK. Angiogenesis and implantation. Hum Reprod. 2000;15:59-66.

41. Miwa I, Tamura H, Takasaki A, Yamagata Y, Shimamura K, Sugino N. Pathophysiologic features of "thin" endometrium. Fertil Steril. 2009;91(4):998-1004

42. Li B, Zhang Q Sun J, Lai D. Human amniotic epithelial cells improve fertility in an intrauterine adhesion mouse model. Stem Cell Res Ther. 2019;10(1):257

43. Na J, Song J, Kim H, Seok J, Kim J, Jun J, Kim G. Human placenta-derived mesenchymal stem cells trigger repair system in TAA-injured rat model via antioxidant effect. Aging. 2020;13(1):61-76. 
44. Chen C, Liu S, Chen C, Chen P, Chen C. Human placenta-derived multipotent mesenchymal stromal cells involved in placental angiogenesis via the PDGF-BB and STAT3 pathways. Biol Reprod. 2015;93(4):103.

45. Xie N, Li Z, Adesanya T, Guo W, Liu Y, Fu M, Kilic A, Tan T, Zhu H, Xie X. Transplantation of placenta-derived mesenchymal stem cells enhances angiogenesis after ischemic limb injury in mice. J Cell Mol Med. 2016;20(1):29-37.

46. Gargett C, Nguyen H, Ye L. Endometrial regeneration and endometrial stem/progenitor cells. Rev Endocr Metab Disord. 2012;13(4):235-51.

47. Shao Y, Wang C, Hong Z, Chen Y. Inhibition of p38 mitogen-activated protein kinase signaling reduces multidrug transporter activity and anti-epileptic drug resistance in refractory epileptic rats. J Neurochem. 2016;136(5):1096-105.

48. Sun Y, Liu W, Liu T, Feng X, Yang N, Zhou H. Signaling pathway of MAPK ERK in cell proliferation, differentiation, migration, senescence and apoptosis. J Recept Signal Transduct Res. 2015;35(6):600-4.

49. Lim W, Bae H, Bazer FW, Song G. Ephrin A1 promotes proliferation of bovine endometrial cells with abundant expression of proliferating cell nuclear antigen and cyclin D1 changing the cell population at each stage of the cell cycle. J Cell Physiol. 2019;234(4):4864-73.

50. Zhou WJ, Hou XX, Wang XQ, Li DJ. Fibroblast growth factor 7 regulates proliferation and decidualization of human endometrial stromal cells via ERK and JNK pathway in an autocrine manner. Reprod Sci. 2017;24(12):1607-19.

\section{Publisher's Note}

Springer Nature remains neutral with regard to jurisdictional claims in published maps and institutional affiliations.

- fast, convenient online submission

- thorough peer review by experienced researchers in your field

- rapid publication on acceptance

- support for research data, including large and complex data types

- gold Open Access which fosters wider collaboration and increased citations

- maximum visibility for your research: over 100M website views per year

At BMC, research is always in progress.

Learn more biomedcentral.com/submissions 